\title{
Does sociability quality of web-based collaborative learning information system influence students' satisfaction and system usage?
}

Maimoona Salam ${ }^{1 *}$ and Muhammad Shoaib Farooq ${ }^{2}$

* Correspondence:

maimoonasalam1@yahoo.com

${ }^{1}$ Faculty of Computer Science and Information Technology, Universiti Malaysia Sarawak (UNIMAS), Kota Samarahan, Kuching, Sarawak, Malaysia

Full list of author information is available at the end of the article

\begin{abstract}
The use of collaborative learning technologies is a stimulating element of collaborative learning process, where social interaction and collaboration are key factors. This research examines the impact of sociability quality on the usage of webbased collaborative learning information system (WBCLIS) and user satisfaction. We propose a theoretical model by integrating the construct of 'sociability quality' in the DeLone and McLean's (Journal of Management Information Systems 19:9-30, 2003) updated information system success model. Proposed theoretical model was empirically validated, in a service-learning course with undergraduate students, where data was collected using an online questionnaire and evaluated through partial least square, structural equation modelling (PLS-SEM) statistical approach. Results suggest that, sociability quality has a direct positive impact on the system use and overall user satisfaction, along with a strong indirect impact on the net benefits of the WBCLIS. Findings also confirmed that, system use and user satisfaction are strong predictors of the net benefits. These results about sociability quality, contribute significantly in the domain of IS success literature, by identifying a novel and critical IS success dimension. Further, theoretical contribution in the context of sociability quality for IS success, and practical implications entailing the use of WBCLIS in the domain of service learning are also discussed.
\end{abstract}

Keywords: Sociability quality, Collaborative learning, Service learning, Information system success, Co-reflective

\section{Introduction}

Online / web-based collaborative learning information system (WBCLIS), offers a webbased social learning environment, which facilitates collaboration between various stakeholders with technological support and pedagogical processes (Al-Samarraie \& Saeed, 2018; Cidral, Oliveira, Di Felice, \& Aparicio, 2018). With recent overwhelming wide range expansion and promotion of the information and communication technologies (ICTs) coupled with better and fast speed access to World Wide Web, internet and advance computing devices (i.e. tablets, laptops, mobile devices), the concept of

(c) The Author(s). 2020 Open Access This article is licensed under a Creative Commons Attribution 4.0 International License, which permits use, sharing, adaptation, distribution and reproduction in any medium or format, as long as you give appropriate credit to the original author(s) and the source, provide a link to the Creative Commons licence, and indicate if changes were made. The images or other third party material in this article are included in the article's Creative Commons licence, unless indicated otherwise in a credit line to the material. If material is not included in the article's Creative Commons licence and your intended use is not permitted by statutory regulation or exceeds the permitted use, you will need to obtain permission directly from the copyright holder. To view a copy of this licence, visit http://creativecommons.org/licenses/by/4.0/. 
social and collaborative learning, has expanded very promptly in higher education worldwide (Molinillo et al., 2018a, b). Prominent examples of advance computer supported learning systems include WebCT, Blackboard and Moodle (Deng \& Tavares, 2013; Salam, Awang Iskandar, Ibrahim, \& Farooq, 2019a, b). Some of them are computer supported collaborative learning (CSCL) systems (e.g. WebCT and other similar knowledge building forums), which are specifically designed for collaborative learning (Hoppe, Soller, \& Ogata, 2007). Whereas, other learning management systems (e.g. Blackboard and Moodle etc.) offer limited inbuilt features and tools for collaboration and social interaction between users (Deng \& Tavares, 2013).

Therefore, various scholars (e.g. Al-Rahmi \& Zeki, 2017; Smith, 2016) have also reported the use of social networking websites (e.g. Twitter, BlogSpot and Facebook etc.), as a platform for academic social interaction and collaborative learning in higher education. Collaborative learning improves students' participation and contribution, by allowing them to interact with each other, in a group learning situation, which provides various opportunities to learn from their social interaction (Liaw, Chen, \& Huang, 2008). The implementation of collaborative learning, especially project-based learning, has been extensively promoted in higher education (Gress, Fior, Hadwin, \& Winne, 2010; Wang, Fang, \& Gu, 2020; Wasko \& Faraj, 2005). For this purpose, specific collaborative learning technologies have been implemented, which have emerged as an important communication tool for students' academic social interaction with each other (Al-Samarraie \& Saeed, 2018; Liao, Huang, Chen, \& Huang, 2015). The effective use of CSCL systems in higher education is well documented, for a number of widespread positive outcomes (e.g. providing spot-on social learning environment, making learning fun, interactive and meaningful etc.), where students can vigorously intricate in the learning process (Kurilovas \& Kubilinskiene, 2020; Martins et al. 2019; Radianti, Majchrzak, Fromm, \& Wohlgenannt, 2020; Rajab \& Eydgahi, 2019; Shen \& Ho, 2020).

Moreover, it enhances students' motivation to learn from social interaction in a peer learning environment, in which collaboration, interaction and active engagement are key factors (Arendt, 2019; Bulotsky-Shearer et al., 2020; Burdelski, 2019; Chen, Park, \& Breazeal, 2020; Kim, Wang, \& Ketenci, 2020; Lowton-Smith et al., 2019). A latest study by Molinillo et al. (2018b) have stated that, social interaction (i.e. students' interaction with other students, and students' interaction with teachers), engagement and social presence are strong determinants of an active learning environment. In this regard, Kreijns and Kirschner (2004) have also asserted that, CSCL systems should provide sociable learning environment for students, by focusing on the social aspects of collaborative learning process. Therefore, programmers and system developers should not undermine the importance of social functionalities, in the collaborative learning process, and their CSCL system should also provide an interactive learning environment (Farooq et al., 2017; Kreijns \& Kirschner, 2004; Salam et al., 2019b). Literature review has shown that, sociability is one of the important elements, that influence the acceptance and use of collaborative technologies (Brown, Dennis, \& Venkatesh, 2010; Gao, Dai, Fan, \& Kang, 2010; Junglas, Goel, Abraham, \& Ives, 2013).

When a system provides all-encompassing social space and tools for interaction and collaboration, it can inevitably increase users' intent to employ that system, which ultimately affects the users' satisfaction and net benefits derived from the performance of a CSCL system (Junglas et al., 2013). In a collaborative learning environment, it's social 
functionalities or sociability quality, allows students to interact, not only to absorb information in a deliberate manner, but it also enables them to attentively ponder, participate, discuss and share their ideas with others (Doumanis, Economou, Sim, \& Porter, 2019; Jiang \& Zhang, 2020; Rosen, Wolf, \& Stoeffler, 2019; Wang et al., 2020; Zhou et al., 2020). Kreijns, Kirschner, Jochems, and van Buuren (2007) have described three major factors, "i.e. sociability, social presence and pedagogical structure", that influence social interaction, and also contribute to the design of a sociable collaborative learning environment. Among these aforementioned factors, sociability is a strong determinant, which defines the propensity of overall system use and user satisfaction towards a CSCL system (Salam et al., 2019b). In this regard, Junglas et al. (2013) have asserted that, along with the technical and functional qualities of an information system, it's social components or sociability also contributes to the acceptance and actual use of an information system.

Regardless of the recognition of this fact, that social component plays an imperative role in the success of a CSCL system, there are very few studies (e.g. Al-Rahmi \& Zeki, 2017; Brown et al., 2010; Gao \& Bai, 2014), that have examined the impact of social factors in a collaborative learning environment. More importantly, analyzing the impact of sociability quality, in combination with DeLone and McLean's (2003) updated IS success model, will not only allow us to evaluate it's influence on system use and user satisfaction, but it will also help in enhancing our understanding, about it's relative importance and contribution towards overall success of a WBCLIS (Salam et al., 2019a, 2019b). For that reason, this study aims to examine the direct impact of sociability quality, on system use and user satisfaction in the context of WBCLIS. For this purpose, a theoretical model is developed and evaluated, by conducting an in-depth empirical study with undergraduate students, who had used a WBCLIS for participating in a group based service learning project. Variance based structural equation modeling (SEM) statistical approach was employed, and data collected through an online self-administered survey, was analyzed, with the help of partial least square (PLS) method.

Next section outlines the detail of WBCLIS system used by our respondents, along with a thorough review of literature on DeLone and McLean's (2003) updated IS success model, and it also defines the concept of sociability and social interaction theory (Gunawardena, 1995; Kreijns et al., 2007; Mills \& Durepos, 2010). Then a detailed discussion on the proposed theoretical model, hypothetical relations and description of constructs is also provided. Research methodology section presents details regarding the design of this study, participants, research setting, methods and approaches used in this study, along with brief overview of data collection and evaluation process. Results section presents the description of empirical findings for measurement and structural models proposed in the theoretical model of this study. At last, discussion section outlines the theoretical contribution and implications of this research, along with limitations and future research directions, followed by a conclusion section for summarizing the outcomes of this study.

\section{Literature review}

\section{Web-based collaborative learning information system (WBCLIS)}

Collaborative learning has become very popular in higher education, for inculcating critical thinking skills and promoting active learning environment, in which group of students work together to attain a shared common learning objective (Al-Samarraie \& Saeed, 2018). Theoretically, collaborative learning is associated with the social constructivism learning 
paradigm (Elia, Solazzo, Lorenzo, \& Passiante, 2019; Mamun, Lawrie, \& Wright, 2020; Shuell, 2001; Tennyson \& Volk, 2015); in which, information sharing and knowledge building is regarded to be significantly influenced, by collaboration and interaction between group members (Curşeu, Rusu, Maricuțoiu, Vîrgă, \& Măgurean, 2020; Hernández-Sellés, Muñoz-Carril, \& González-Sanmamed, 2019; Molinillo et al. 2018a; Tan, 2019; Williamson et al., 2020). In the context of collaborative learning, in-group collaboration is often regarded as an affirmative forte, that aids students in the achievement of their shared common goals, while simultaneously upholding their own individual level learning goals (Lee, 2014).

In this modern age of artificial intelligence and advance technology enabled devices, access to fast speed internet has led to a widespread use and acceptance of collaborative learning, by facilitating the formation of online dialogical interaction between teachers and students (Molinillo et al., 2018a). More particularly, WBCLIS have been especially developed in recent past, to enhance the overall connotation and meaningfulness of the social interaction, for fostering the presence of an active learning environment (Molinillo et al., 2018a; Salam et al., 2019b). WBCLIS refers to a set of tools, that are specifically designed for promoting collaborative learning, through meaningful interaction, expressive knowledge sharing and frequent inter-linked goal oriented group activities (Cheung \& Vogel, 2013). Most of the literature (e.g. Cheung \& Vogel, 2013; Farrokhnia, PijeiraDíaz, Noroozi, \& Hatami, 2019; Garcia-Sanjuan, Jurdi, Jaen, \& Nacher, 2018; Hernández-Sellés et al., 2019; Liaw et al., 2008; Reis et al., 2018), which reviewed the significance and use of CSCL systems, has been built on the fundamentals of cognitive science and social constructivist theory only (Holenko Dlab, Boticki, HoicBozic, \& Looi, 2020; Jeong, Hmelo-Silver, \& Jo, 2019; Weimer, Parault Dowds, Fabricius, Schwanenflugel, \& Suh, 2017; Zheng, Li, Zhang, \& Sun, 2019). Thereby, previous studies (e.g. Cheung \& Vogel, 2013; Farrokhnia et al., 2019; HernándezSellés et al., 2019; Liaw et al., 2008; Shen, 2012) have overlooked various dimensions, important to the functionalities of a WBCLIS system (Garcia-Sanjuan et al., 2018; Reis et al., 2018; Salam, 2020).

Specifically, WBCLIS are designed in such a way, that enables them to provide optimum computing functionalities, quality information and internet technologies, that can foster the interaction between students and teachers, for enhancing a seamless flow of information and sharing of knowledge (Liaw et al., 2008). According to Molinillo et al. (2018b), WBCLIS provides opportunities for students, to become more responsible and active learner, not only to absorb and exchange information, but also to easily reflect back, and straightforwardly link their previous knowledge, with the newly comprehended information on the subject matter. In recent few years, a rising trend of widespread application of collaborative learning, by means of advance technologies (i.e. WBCLIS and other similar virtual learning systems), has been witnessed, in the world over higher education / academic industry. Thereby, WBCLIS and other similar technologies have become an integral part of collaborative learning, which has been increasingly implemented, as an essential element of service learning pedagogy, in the top ranked institutions of higher education, around the globe (Al-Samarraie \& Saeed, 2018; Cheung \& Vogel, 2013; Molinillo et al., 2018a). 
With reference to the above discussion, it is pertinent to note that, collaborative learning is mediated by technology, that facilitates a collaborative learning environment, in which necessary pedagogical and social functionalities are provided (Chan \& Pow, 2020; Isohätälä, Järvenoja, \& Järvelä, 2017; Lin, 2020; Molinillo et al., 2018b). In a collaborative learning tool, it is crucial to provide social features, that can facilitate and encourage the social interaction among teachers and students (Molinillo et al., 2018a). So that, students can gain deeper insights, for comprehending the multidimensional aspects of new knowledge, exchange their views and develop their independent opinion, along with cognitive skills, by participating in a socially supportive collaborative learning process (Kreijns et al., 2007; Molinillo et al., 2018a). Where many proponents (e.g. Atan, Rahman, Majid, \& Dahlan, 2012; Doumanis et al., 2019; Jan, Chen, \& Huang, 2016; Mata-Rivera, Torres-Ruiz, Guzmán, Moreno-Ibarra, \& Quintero, 2015; Molinillo et al., 2018a; Molinillo et al., 2018b) support the use of WBCLIS, and acknowledge it's significance, for facilitating the collaborative learning process. Still, some opponents (e.g. Fleaca \& Stanciu, 2019; Krishnakumar \& Nogales, 2020; Njenga, Garg, Bhardwaj, Prakash, \& Bawa, 2019; Pinho, Franco, \& Mendes, 2019) argue that, collaboration through WBCLIS, presents some operational difficulties, that must be considered. For instance, with respect to the face-to-face collaboration, collaborative learning through WBCLIS requires certain IT skills and computer knowledge (Doumanis et al., 2019; Jeong et al., 2019).

Moreover, students as well as teachers, also have to spend substantial amount of their time, for understanding the operational functionalities of a given WBCLIS (Atan et al,, 2012; Jan et al., 2016). Further, successful implementation of a WBCLIS do require dedication and candid efforts from both, teachers and students, to actively participate in the collaborative learning activities, for achieving their shared goals, while simultaneously maintaining their individual beliefs through self-learning, comprehension and with a reflection of comparative analysis of their previous acquaintance, with newly acquired information (ChanLin, 2012). Moreover, teachers should clearly define the collaborative learning activities, along with outlining their own role in the planning, execution and evaluation of whole collaborative learning process (Churchill, 2011). Additionally, it is important to enrich a WBCLIS system, with various social features and tools, to facilitate in-group collaboration, social interaction and social presence, which are rationally very important, for the success of whole collaborative learning process (Kreijns et al., 2007; Kreijns, Van Acker, Vermeulen, \& Van Buuren, 2014; Kreijns, Kirschner, \& Vermeulen, 2013; Yamada, Goda, Matsukawa, Hata, \& Yasunami, 2016).

\section{Information system success}

In this era of fast pace technological advancements, majority of the modern businesses are heavily relying on modern IS systems; thereby, becoming more dependent on IT, for accomplishing their daily routine operations (Farooq 2018; Salam 2020). Moreover, world over various departments of large size corporations, also count on IS, for attaining success in their different organizational goals (Grabowski \& Roberts, 2019; Modaresnezhad, Iyer, Palvia, \& Taras, 2020; Prys, Krysińska, Janaszkiewicz, Winiecki, \& Różewski, 2018; Wang \& Zhao, 2020). Therefore, acceptance and use of technology 
has also remained a subject of interest for many academicians (e.g. Baishya \& Samalia, 2019; Farooq et al., 2017; Oviedo-Trespalacios, Briant, Kaye, \& King, 2020; Tao et al., 2020; Tsertsidis, Kolkowska, \& Hedström, 2019). Moreover, previous studies (e.g. AlFraihat, Joy, Masa'deh, \& Sinclair, 2020; Cheung \& Vogel, 2013; Pinho et al., 2019; Shim \& Jo, 2020; Yuan, Chu, Lai, \& Wu, 2020) have suggested several factors (i.e. technological, behavioral and organizational etc.), that determine the effective use, acceptance, adoption and success of an information system. Various technology related models (e.g. Davis, 1989; Farooq et al., 2017; Venkatesh, Morris, Davis, \& Davis, 2003; Venkatesh, Thong, \& Xu, 2012) have only focused on the pre-adoption stage of technology, by putting more emphasis on the acceptance of technology only; thereby, downplaying on the actual outcomes, success and benefits of an information system.

In this context, DeLone and McLean's (1992) IS success model and DeLone and McLean's (2003) updated IS success model, are commonly used frameworks for explaining the cognitive and behavioral facets, of the system's post-adoption (i.e. after acceptance of system) stage, system use and system success (Aparicio, Bacao, \& Oliveira, 2017; Tam \& Oliveira, 2017; Veeramootoo, Nunkoo, \& Dwivedi, 2018). IS success model, first introduced by DeLone and McLean (1992) encompasses six major constructs, "i.e. information quality, system quality, user satisfaction, system use, individual impact and organizational impact". DeLone and McLean's (1992) IS success model is often braced for two main reasons, i.e. (1) it presents an in-depth description of many IS success elements and indicators, in a solo, yet comprehensive theoretical framework, (2) this model suggests a time-based and causal interdependence among different categories of indicators of IS success (Veeramootoo et al., 2018; Wang \& Liao, 2008). In response to the modification in advance IS environment, DeLone and McLean's (1992) IS success model was updated, with the inclusion of a new construct, "i.e. service quality" (DeLone \& McLean, 2003).

By introducing the concept of service quality, DeLone and McLean's (2003) updated IS success model, has enhanced the researchers' propensity to measure and analyze the quality of service, provided by IT department, for a particular information system (Tam \& Oliveira, 2017). Literature review has revealed that, DeLone and McLean's (1992) IS success model and DeLone and McLean's (2003) updated IS success model, have been frequently applied, for the evaluation of usage and success of various information systems, in several different contexts. For instance, success of e-learning systems (e.g. Aldholay, Isaac, Abdullah, Abdulsalam, \& Al-Shibami, 2018; Al-Samarraie, Teng, Alzahrani, \& Alalwan, 2017; Aparicio et al., 2017; Cidral et al., 2018; Wang \& Chiu, 2011), success of e-commerce systems (e.g. DeLone \& McLean, 2004; Tam \& Oliveira, 2017) and success of e-government systems (e.g. Finney \& Corbett, 2007; Mukred \& Yusof, 2018; Rizal, Yussof, Amin, \& Chen-Jung, 2018; Veeramootoo et al., 2018; Wang \& Liao, 2008). However, these aforementioned scholars (i.e. Al-Samarraie et al., 2017; Aparicio et al., 2017; Cidral et al., 2018; DeLone \& McLean, 2004; Finney \& Corbett, 2007; Mukred \& Yusof, 2018; Rizal et al., 2018; Tam \& Oliveira, 2017; Veeramootoo et al., 2018; Wang \& Liao, 2008) do not have a unanimous and concerted take, on the dimensions and definition of the success of an information system (Salam, 2020).

The concept of measuring success in the field of IT, is a multidimensional facet, and it's various dimensions, can be considered, as distinct indicators of success of an information system (Aldholay et al., 2018; Aparicio et al., 2017; Mukred \& Yusof, 2018; 
Wang \& Chiu, 2011). According to Martins et al. (2018) the perception of IS success can vary, depending on the different type, purpose (i.e. operational functionality of an information system) and nature of an information system. For example, there are several studies (e.g. Al-Samarraie et al., 2017; Kim \& Malhotra, 2005; Mohammadi, 2015) which have regarded the continuous usage, of a particular system, as a measure of IS success. However, some academicians (e.g. Al-Samarraie et al., 2017; Martins et al., 2018; Zolotov, Oliveira, \& Casteleyn, 2018) assert that, continuous usage of a system can be a potential outcome of not having any other choice (e.g. a situation in which students have no option, but to register and enroll through a less user-friendly online registration portal). Therefore, continuous usage is not a real indication of the success of an information system (Al-Samarraie et al., 2017; Martins et al., 2018; Zolotov et al., 2018).

According to Zolotov et al. (2018), real success of an e-participation system, can be measured with the citizens' overall satisfaction and intention to adopt the particular system, for a longer period of time. Further, Martins et al. (2018) and Al-Samarraie et al. (2017) have taken users' continued satisfaction, as a fomented indication of the success of an e-learning system. While DeLone and McLean's (2003) updated IS success model has received much support, and it has been efficaciously applied, for the evaluation of various information systems, since many decades. Still, various scholars (e.g. Aldholay et al., 2018; Farooq et al., 2017; Mukred \& Yusof, 2018; Salam et al., 2019b) have called for further research, in the domain of success of information systems. More in-depth studies are warranted, to answer the call for research in this domain (Aldholay et al., 2018; Farooq et al., 2017; Mukred \& Yusof, 2018; Salam et al., 2019b). Therefore, this study is aimed to extend the existing DeLone and McLean's (2003) updated IS success model, to assess different new aspects, specific to the success of an information system, by incorporating the concept of "sociability quality", which is an important element and indicator for assessing the success of a WBCLIS.

This study is grounded on the concept of rationality, and therefore, it is submitted that, different constructs, which are relevant to different situations, should be assessed along with the concept of "sociability quality" for assessing the significance of a WBCLIS. While convening the assessment of education related information systems, it is essential to consider the concept of sociability and collaboration, along with other factors, that can be effective, for facilitating the teaching and learning processes (Martins et al. 2018, 2019; Salam 2020). Collaborative learning technologies have emerged as a wide set of tools, that offer a flexible and eloquent kind of socially interactive platform for collaborative learning (Chan and Pow 2020; Tan 2019). Although, some social networking websites and purpose built e-learning applications, also provide functional support and tools for online collaboration, still the debate about the importance of WBCLIS, between it's proponents and opponents cannot be to put to rest, without further in-depth investigation of the subject matter (Atan et al. 2012; Doumanis et al. 2019; Mata-Rivera et al. 2015).

Previous studies have also evaluated different types of education related information systems; for instance, Martins et al. (2018) have evaluated the success of education management system, and Cidral et al. (2018) reported the success factors of e-learning system. However, still the significance and success factors of sociability features, offered by WBCLIS, are not completely known to date (Salam, 2020). Therefore, in an effort to 
address this gap in the IS literature, this study incorporates a new construct of "sociability quality" (i.e. adapted from Kreijns et al.'s (2004, 2007, 2002) concept of sociability for CSCL systems) in the DeLone and McLean's (2003) updated IS success model, to explore the success factors of a WBCLIS. In this context, this study argues that, sociability component (i.e. sociability quality) is as much important, for a WBCLIS, as are it's other components, related to system quality or information quality etc. Following section presents more details, regarding major constructs involved in this study, along with hypotheses development and proposed theoretical model, for assessing the sociability quality of a WBCLIS.

\section{Constructs, hypotheses development and proposed theoretical model System quality}

The functional eminence and quality of CSCL systems is considered their imperative chip, for offering a smooth collaborative learning experience, in a project based collaborative learning context (Dado and Bodemer 2017; Jeong et al. 2019; Lin et al. 2016; Zheng et al. 2019). Therefore, system quality has a significant impact on the functionality, performance characteristics and usability of a CSCL system (Bhuasiri et al. 2012; Cidral et al. 2018). System quality, of a CSCL system, is described as it's functional and technical characteristic (Garcia-Sanjuan et al. 2018; Suebnukarn and Haddawy 2006; Ward 1998). Information systems are expected to have a momentous level of system quality, because it has a significant impact on the overall acceptance and adoption of a system (von Hellens 1997; Rangraz Jeddi et al. 2020; Salmela 1997). Moreover, it is an indispensable dimension, of the usefulness, of any information system (von Hellens 1997; Rangraz Jeddi et al. 2020). System quality defines the extent, to which an information system is successful, in real world environment, for performing multiple simultaneous functions, while achieving the agreed upon deliverables, by it's all stakeholders (von Hellens 1997; Martins et al. 2018; Rangraz Jeddi et al. 2020). Previous studies (e.g. Aparicio et al. 2017; Balaban et al., 2013; Cidral et al. 2018; Martins et al. 2018) have also acknowledged that, system quality has a direct positive influence on the system use and user satisfaction.

System quality reflects the attainment of basic functionalities, in an efficient and evocative manner, for what a specific system was developed (von Hellens 1997; Martins et al. 2018; Rangraz Jeddi et al. 2020; Salmela 1997). More precisely, for education related information systems, their pedagogical functionalities are essential features, that enable users to effectively and efficiently interconnect with the system, for teaching and learning activities (Apostolou et al. 2014; Forster et al. 2020; Hamidi and Jahanshaheefard 2019; Martins et al. 2019). Moreover, CSCL systems are helpful in accessing online academic resources (e.g. course outlines and course contents etc.), along with information sharing, regarding other allied learning opportunities (e.g. upcoming events / milestones achieved during the course etc.), while promoting a dynamic interaction between teachers and students, throughout their whole learning process (Aparicio et al., 2016; Martins et al. 2018). In addition to this, Urbach et al. (2010) and Tarhini et al. (2017) have also emphasized on the importance of system structure, graphical logic design, accessibility, navigational suppleness, sustainability and reliability of online learning systems, as the indicators of a system's operational quality. System quality is important to ensure the overall eminence, 
of collaborative learning experience, offered by a WBCLIS (Rangraz Jeddi et al. 2020; Salam 2020; Shim and Jo 2020).

While assessing the acceptance and usefulness of CSCL systems or similar educational technologies, users' satisfaction towards these systems, coupled with their functional and technical quality, is always considered as an imperative factor (Apostolou et al. 2014; Atan et al. 2012; Forster et al. 2020; Hamidi and Jahanshaheefard 2019). In this context, Martins et al. (2018) and Cidral et al. (2018) have also argued that, overall quality of education-related information systems (i.e. also referred as e-learning systems) should be assessed on the base of systems' ability to be used easily, along with its' ability to persistently and appropriately, offer all necessary features, in a standardized and sustainable manner. Attainment of various modulated aspects, along with mutually predefined features, required by all users and stakeholders, is a constituent prerequisite of a CSCL system's quality (Aslan and Hamurcu 2015; Dado and Bodemer 2017; Gress et al. 2010; Reis et al. 2018; Zheng et al. 2019). Though, previous studies on system quality (e.g. Aparicio et al. 2017; Balaban et al. 2013; Cidral et al. 2018; Martins et al. 2018) have explored it's significance, for various other systems (e.g. elearning / education management information systems, and e-portfolio systems etc.); however, less is known about the impact of system quality, on the system use and user satisfaction, in the case of WBCLIS. Therefore, further studies are required, to address this research gap, in IS literature (Balaban et al. 2013; Martins et al. 2018; Salam et al. 2019a). Developing on the aforementioned coherent arguments, this study submits following propositions:

H1a: System quality has a positive impact on system use

H1b: System quality has a positive impact on user satisfaction

\section{Information quality}

Information quality of a system, represents the characteristics of an information, generated as an output of a particular system (DeLone and McLean 2003; Riesener et al. 2019; Timmerman and Bronselaer 2019; Zhang et al. 2020). Information quality has been measured by evaluating the reliability, accuracy and trustworthiness of the information and results, produced by a specific system (Gerber et al., 2004; Michel-Verkerke 2012; Ojo 2017; Rangraz Jeddi et al. 2020; Shim and Jo 2020). In the context of online learning and CSCL, information quality particularly refers to the extent, to which system users perceive, that learning or education related academic information, available through their CSCL system, is adequate, accurate, reliable, comprehensive, relevant, organized and up-to-date for a rewardingly decent learning experience (Aldholay et al. 2018; Cidral et al. 2018; El-Masri and Tarhini 2017). Information quality has a strong influence on students' satisfaction, system success and net benefits (Balaban et al. 2013; Cidral et al. 2018; Costa et al. 2016). Moreover, information quality, determines the tendency towards system use, and users' overall satisfaction; therefore, various studies (e.g. Aparicio et al. 2017; Balaban et al. 2013; Bhuasiri et al. 2012; Cidral et al. 2018; Wang and Chiu 2011) have described that, information quality is an important factor, for the success of any e-leaning system. 
In various distance learning programs (i.e. also known as online education system), students spend their considerable time and efforts to acquire education related academic information, for a productive e-learning experience (Al-Samarraie et al. 2017; Churchill 2011; Martins et al. 2018). Same is the case, with blended education system, offering service learning, through a collaborative environment (Mukred and Yusof 2018; Rangraz Jeddi et al. 2020; Salam et al. 2019a). According to Martins et al. (2018), academic institutions are responsible to ensure that, all information shared on the platform of their CSCL system is accurate, reliable and organized, in a way, that facilitates the conferring of whole learning processes. Previous studies on e-learning and CSCL (e.g. Aparicio et al. 2017; Balaban et al. 2013; Bhuasiri et al. 2012; Cidral et al. 2018; Wang and Chiu 2011) have found that, standard and quality of information characteristics, are positively linked to system use and users' satisfaction. However, significance of information quality, in the context of WBCLIS, has remained largely unaddressed, by most of the aforementioned studies (Atan et al. 2012; Liaw et al. 2008; Shen 2012). Therefore, in order to address this gap, in the IS literature, regarding the evaluation of WBCLIS, this study submits that:

H2a: Information quality has a positive impact on system use.

H2b: Information quality has a positive impact on user satisfaction.

\section{Service quality}

Service quality is another important dimension of IS success (Li and Shang 2019; Martins et al. 2018; Ojo 2017; Yang et al. 2017). DeLone and McLean's (2003) updated IS success model postulates that, quality of service, has a significant impact on the system use and subsequent user satisfaction. Service quality denotes to the quality of professional support and after deal service, provided by the system administrators and developers (Al-Fraihat et al. 2020; Bharati and Berg 2005; Li and Shang 2019; Mohammadi 2015; Shim and Jo 2020). Service quality of a CSCL system is assessed through various attributes, e.g. responsiveness, readiness, reliability, assurance, suppleness, interactivity and facility of tutorial / training for users, to help them in utilizing all features of a system (Aldholay et al. 2018; Ojo 2017; Urbach et al. 2010; Wang and Teo 2020). In the perspective of success, of online education / e-learning systems, findings reported by previous studies (e.g. Aparicio et al. 2017; Balaban et al. 2013; Wang and Chiu 2011) have demonstrated a positive association, between users' perceived service quality and system use. A recent study by Yang et al. (2017), reported a positive relationship, among service quality and users' long term intention to use open source online academic systems. Moreover, service quality is also a strong determinant, of users' satisfaction towards e-learning systems (ChanLin 2012; Farooq et al. 2018; Martins et al. 2018; Veeramootoo et al. 2018).

When considering education-related information systems, the perceived service quality, has a high impact on users' overall satisfaction level (Bhuasiri et al. 2012; Mohammadi 2015; Urbach et al. 2010). If service quality is high, it increases users' satisfaction; thereby, discouraging them from opting any other alternatives (Balaban et al. 2013; Bharati and Berg 2005; El-Masri and Tarhini 2017; Shim and Jo 2020). Moreover, recently Cidral et al. (2018) and Martins et al. (2018) have also validated a positive 
association, among service quality and system use. However, this study argues that, WBCLIS have a unique nature, as they offer a platform for social collaboration, between teachers and students. Therefore, more studies are warranted, to explore the phenomenon of service quality, for WBCLIS, to better understand all the facets, of their use and users' satisfaction towards WBCLIS. For that reason, based on the above discussion, this study submits following hypotheses in the context of WBCLIS:

H3a: Service quality has a positive impact on system use.

H3b: Service quality has a positive impact on user satisfaction.

\section{Sociability quality}

According to Kreijns et al. (2007:176) sociability of a CSCL system refers to "the extent to which a CSCL environment is perceived to be able to facilitate the emergence of a sound social space with attributes as trust and belonging, a strong sense of community, and good working relationships" (Kreijns et al. 2007:176). Sociability of a CSCL system, can be measured with it's ability, to serve as a reliable mediated environment, to assist the development, of a strong social and collaborative relationship, between it's all users (e.g. students and teachers etc.) and stakeholders (Gao et al. 2010; Junglas et al. 2013; Kreijns et al. 2004, 2007, 2002; Salam et al. 2019b, Salam et al., 2019a; Yamada et al. 2016). Further, Gao et al. (2010) have examined the relation, between sociability of a social software and it's impact on users' attitude and intention, towards long term use of a particular software. Findings of Gao et al. (2010) have confirmed that, sociability has a strong and significant influence on both, users' attitude towards initial application of the social software, and their intention to use, that particular software, for a longer period of time.

Likewise, another study by Junglas et al. (2013) has also confirmed that, sociability (i.e. taken as a social component) has a positive impact on system use, and it has a significant role, in determining users' overall tendency, towards technology acceptance. Moreover, various other studies (e.g. Gao et al. 2010; Junglas et al. 2013; Kreijns et al. 2007; Kreijns and Kirschner 2004; Oksanen and Hämäläinen 2013) have also acknowledged the significance of sociability component, and have attributed the presence of sociability, for it's contributions, towards maximizing the usage of collaborative technologies. Although, aforementioned studies (e.g. Gao et al. 2010; Junglas et al. 2013; Kreijns et al. 2007; Kreijns and Kirschner 2004; Oksanen and Hämäläinen 2013) have explored the concept of sociability, for it's significance, in enhancing system use. Yet, absence of a comprehensive framework for assessing sociability of WBCLIS, is still a major gap, in the IS literature (Salam 2020; Salam et al. 2019b).

As mentioned earlier, DeLone and McLean's (2003) updated IS success model is most acclaimed and commended comprehensive framework, for explaining and assessing the success of information systems. Since, aforementioned studies on the sociability component (e.g. Gao et al. 2010; Junglas et al. 2013; Kreijns et al. 2007; Kreijns and Kirschner 2004; Oksanen and Hämäläinen 2013) have not investigated the concept of sociability, in the presence of other IS success factors, identified by DeLone and McLean's (2003) updated IS success model. Therefore, this study argues that, previous work on the component of sociability (e.g. Gao et al. 2010; Junglas et al. 2013; Kreijns 
et al. 2007; Kreijns and Kirschner 2004; Oksanen and Hämäläinen 2013), has failed to offer a complete picture, of all the facets of sociability, in the context of WBCLIS. For that purpose, more studies are required, to explore the element of sociability, in the context of WBCLIS.

Building on the aforementioned, Kreijns et al.'s (2004, 2007, 2002) concept of sociability for CSCL systems, this study suggests that, WBCLIS have more to offer, in terms of a collaborative and social platform for higher education (ChanLin 2012; Jan et al. 2016; Salam 2020; Shen 2012). Further, this study argues that, mere presence of sociability features is not enough, for collaboration between teachers and students, rather high quality of sociability, is what makes a WBCLIS successful. Therefore, inspired by Kreijns et al.'s (2007) concept of sociability for CSCL, this study proposes a new terminology / dimension of quality (i.e. sociability quality), to be assessed along with three existing quality dimensions, "i.e. system quality, information quality and service quality" of DeLone and McLean's (2003) updated IS success model. This study defines sociability quality, as the degree, to which a WBCLIS is capable, of offering eminent support, for online social interaction, as a dependable and trustworthy platform, for collaboration between teachers and students. Moreover, this study asserts that, similar to the three major quality components of DeLone and McLean's (2003) updated IS success model, "i.e. system quality, information quality and service quality", sociability quality is also an important facet, which has been overlooked in previous IS literature (Al-Fraihat et al. 2020; Vitale and Udell 2019; White et al. 2017; Yoder et al., 2019). Therefore, with respect to the preceding discussion, on the concept of sociability, sociability quality and importance of social collaboration in WBCLIS, this study submits following hypotheses:

H4a: Sociability quality has a positive impact on system use.

H4b: Sociability quality has a positive impact on user satisfaction.

\section{User satisfaction}

User satisfaction is known as one of the imperative factors, for evaluating the success of an information system (Balaban et al. 2013; Forster et al. 2020; Ojo 2017; Salam 2020; Santa et al., 2019; Xu and Du 2019). Various studies (e.g. Aldholay et al. 2018; DeLone and McLean 2003) have confirmed that, user satisfaction has a direct and significant relationship, with overall system use. User satisfaction is described as, the extent to which, a user, perceives a particular CSCL system, to be useful and effective, for achieving his / her objectives (DeLone and McLean 2004). In the context of online education / e-learning, various scholars (e.g. Aparicio et al. 2017; Cidral et al. 2018; Hassanzadeh et al., 2012; Wang and Liao 2008) have emphasized on the importance of user satisfaction. User satisfaction of an academic information system, is determined by the extent, to which it's users (i.e. teachers and students etc.) are contented with the system functionalities, for a productive learning experience, and how well is it's performance, to meet the expectations of all the stakeholders (Aparicio et al. 2017; Cidral et al. 2018; Hassanzadeh et al. 2012; Wang and Liao 2008).

User satisfaction towards a WBCLIS, is also reflected by users' intention and willingness, to use it, again and again, for a longer period of time (DeLone and McLean 2004; 
Gluck 1996; Salam 2020). Among all the internal and external stakeholders; students, who are using an e-learning system, are the real legatees, of a CSCL system (Hassanzadeh et al. 2012; Salam 2020). The relationship among system use and user satisfaction, has been validated, in a number of studies (e.g. Al-Samarraie et al. 2017; Balaban et al. 2013; Martins et al. 2018), conducted in the domain of elearning information systems. Specifically, in the context of WBCLIS, Salam (2020) has acknowledged that, if a user is more satisfied with a particular system, his / her intention to use that particular system, is proportionately enhanced. Further, Cidral et al. (2018) while performing a review of online education / e-learning systems' effectiveness, argued that, measurement of user satisfaction, is crucial in the context of e-learning, to assess the long term adoption of an information system, used for academic purposes.

Moreover, according to Balaban et al. (2013) and Martins et al. (2018), user satisfaction is also a strong determinant, of the net benefits of an information system. Although, aforementioned studies (e.g. Al-Samarraie et al. 2017; Aparicio et al. 2017; Balaban et al. 2013; Cidral et al. 2018; Hassanzadeh et al. 2012; Martins et al. 2018; Wang and Liao 2008), have thoroughly explained the concept of user satisfaction (Mellikeche et al. 2020; Salam 2020). However, this study argues that, WBCLIS itself is unique, in it's nature; and therefore, it's success is determined by it's sociability quality (Salam 2020; Santa et al. 2019). For that reason, impact of user satisfaction, on overall system use and net benefits, warrants more research, in the domain of modern academic information systems, specifically with the reference of WBCLIS (Mellikeche et al. 2020; Salam 2020; Xu and Du 2019). Therefore, developing on the base of above mentioned logical arguments, and in order to extend our understanding, regarding the role of user satisfaction, in the context of WBCLIS, this study hypothesizes that:

H5: User satisfaction has a positive impact on system use.

H6: User satisfaction has a positive impact on net benefits.

\section{System use}

System use denotes to the extent to which a user uses, the entire spectrum, of the available features, in a particular system, to fulfill his / her needs (Handayani et al. 2019; Li et al. 2020; Muczyński et al., 2019; Salam 2020). More precisely, system use is concerned with evaluating, the overall use of an information system, by its' users (El-Masri and Tarhini 2017; Farooq et al. 2017; Liaw et al. 2008). Various previous studies (e.g. Alzahrani et al. 2017; Balaban et al. 2013; El-Masri and Tarhini 2017; Farooq et al. 2017; Salam 2020) have measured the concept of system use, with a number of different aspects, e.g. frequency of system use, nature and duration of system use, and users' perception towards perceived usefulness and effectiveness of a system, for fulfilling their needs. Additionally, aforementioned studies (e.g. Alzahrani et al. 2017; Balaban et al. 2013; El-Masri and Tarhini 2017; Farooq et al. 2017; Salam 2020) have also demonstrated that, various factors influence the long term use of an e-learning system, e.g. ease of use, and the provision of quality information etc. Moreover, systems' reliability and functional structure, for facilitating the collaborative learning process, also effects the use of a CSCL 
system, in higher education (Gress et al. 2010; Reis et al. 2018; Salam 2020; Zheng et al. 2019).

Various allied features, e.g. start-up guidelines, tutorials and instruction manuals, also facilitate the use and acceptance of a CSCL system (Handayani et al. 2019; Li et al. 2020; Muczyński et al. 2019; Salam 2020). Moreover, a fair level of backup support, also offers a peace of mind, which usually leads to increase in system use, followed by an upsurge, in the overall net benefits (Gelderman 1998; Gluck 1996; Martins et al. 2019; Muczyński et al. 2019; Rangraz Jeddi et al. 2020; Salam 2020). Recently, Martins et al. (2018) have also confirmed, a strong and positive connection, among the use of education related information systems / e-learning systems, user satisfaction and apparent net benefits. Moreover, with reference to education related information systems, both Balaban et al. (2013) and Martins et al. (2018) have also reported a positive association, between system use and it's inherent net benefits. However, this study argues that, as a social platform, outcomes of collaborative learning process, through WBCLIS can only be materialized in terms of it's net benefits, when all users (i.e. teachers and students etc.) have a relationship of mutual trust (Handayani et al. 2019; Li et al. 2020; Salam 2020). A relationship of trust and confidence, between group members, is developed by continuous use of a WBCLIS, which leads to an increase in the net benefits (Muczyński et al. 2019; Salam 2020; Santa et al. 2019).

WBCLIS offers a convenient way, to implement collaborative learning, in the service learning pedagogy (Muczyński et al. 2019; Salam 2020; Salam et al. 2019a). As a popular mode of experiential learning, in-group collaboration, is a hallmark of service learning projects, which is made possible, with the right and timely, implementation of WBCLIS (Li et al. 2020; Salam 2020). However, not much is known, about the net benefits, derived from the use of a WBCLIS to date (Handayani et al. 2019; Salam 2020; Salam et al. 2019c; Santa et al. 2019). Therefore, extending the work of aforementioned studies (e.g. Balaban et al. 2013; Martins et al. 2018; Salam 2020), this study suggests that, system use of WBCLIS can offer more net benefits to users, as a platform of social information sharing and collaborative learning. In order to explore the proposition of positive connection, among system use and increase in net benefits, in the context of WBCLIS, this study submits following hypothesis:

H7: System use has a positive impact on net benefits.

\section{Net benefits}

The concept of net benefits is defined, as to what extent, an information system, adds to the accomplishments of an individual, group, or an organization (Alzahrani et al. 2017; DeLone and McLean 2003; Hassanzadeh et al. 2012; Makhni 2020). The construct of net benefits is designed to encompass, all expected benefits of an information system, for its' different stakeholders (Bhuasiri et al. 2012; Urbach et al. 2010; Zhang and Thompson 2019). In the initial version of DeLone and McLean's (1992) IS success model, outcomes and contributions of an information system, were measured as a manifestation, of it's overall individual impact or organizational impact (Hendra, S. Kom., and Arifin, S. Kom., 2018; Love et al., 2020; Salam 2020). However, developing on DeLone and McLean's (2003) updated IS success model, this study has examined 
the contributions, of a WBCLIS as it's net benefits. According to Balaban et al. (2013) the connotations of net benefits, are elusive in nature and therefore, net benefits are case specific. Moreover, Balaban et al. (2013) have noted that, the concept of net benefits may differ, according to the needs of each user, and it is totally dependent on the type and objectives of an information system.

Various scholars (e.g. Alzahrani et al. 2017; Anaya 2013; Balaban et al. 2013; DeLone and McLean 2003; Kurkalova and Carter 2017; Marnewick 2016; Martins et al. 2018; Salam 2020) have acknowledged that, the determinants of net benefits, are not fully known to date. Therefore, Balaban et al. (2013) and Martins et al. (2018) have asserted, on the need for more studies, to explore the determinants of net benefits, in the domain of education related information systems (Peña-Miguel and De La Peña 2018; Salam 2020; Yang and Lam 2019). Answering their call for more studies, in the domain of IS, for exploring new IS success dimensions, this study has proposed "sociability quality" as a new proponent of the net benefits, in the DeLone and McLean's (2003) updated IS success model.

\section{Theoretical model}

Above-mentioned sections have presented an in-depth discussion, regarding a number of success factors, that can practically add to the success, of an information system. On the base of previously mentioned, detailed discussion on the subject matter, and developing on the logical propositions submitted earlier, a proposed theoretical model is presented in Fig. 1. Considering the unique nature of sociability, for collaborative learning, in a WBCLIS, this proposed theoretical model, integrates sociability quality, as an exogenous construct, and as a success dimension, for WBCLIS system use and user satisfaction. Hence, proposed theoretical model comprises of four exogenous independent variables, "i.e. system quality, information quality, service quality and sociability quality", and three endogenous dependent variables, "i.e. user satisfaction, system use and net benefits".

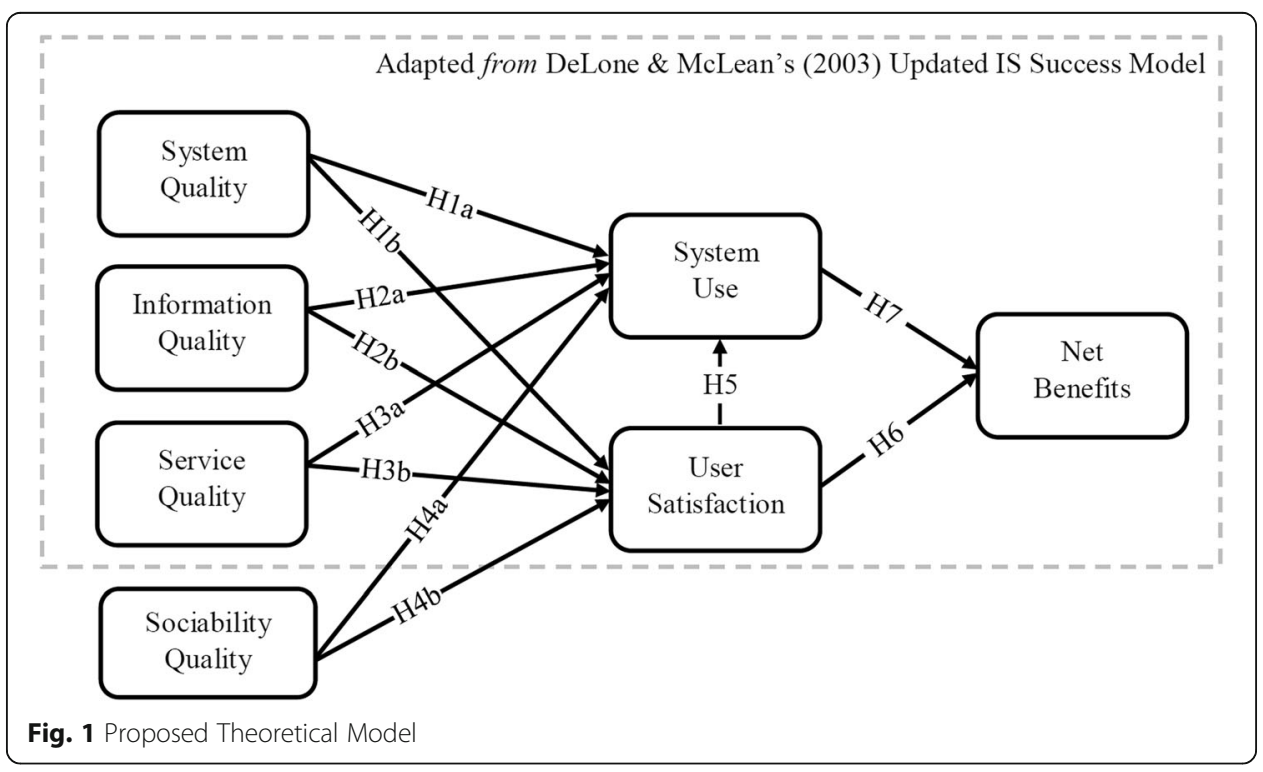


As described earlier, this study is aimed to assess the role of sociability quality, in determining the success of WBCLIS users' satisfaction and system usage. Therefore, in order to assess user satisfaction, system use and other IS success factors, in the context of WBCLIS, a comprehensive multi-construct theoretical model is proposed in this study (see Fig. 1). By proposing a new construct of "sociability quality", this study has extended the DeLone and McLean's (2003) updated IS success model, for assessing the sociability component of WBCLIS. It is expected that, sociability quality will help in explaining the hidden facets, of new IS success dimensions (Salam 2020; Vitale and Udell 2019; White et al. 2017). Proposed theoretical model of this study, is assessed by evaluating the success of a newly developed WBCLIS, implemented for facilitating the teachers and students, working on a collaborative service learning project, in a public sector university, in Malaysia. Further discussion regarding the assessment approach and research methodology, used for assessing the proposed theoretical model of this study, is described in next section.

\section{Research methodology}

Design of the Study

Proposed theoretical model of this study, integrates sociability quality, in the DeLone and McLean's (2003) updated IS success model. Therefore, this study is exploratory in nature, and is aimed to explore the relationship, of sociability quality, with the system use, user satisfaction and net benefits of a WBCLIS. Moreover, this study is an effort of it's own kind, which has assessed, the success dimensions of a WBCLIS, with a practical approach, in the project based collaborative and service learning context. As a practical part of this study, a flagship WBCLIS (i.e. the Co-Reflective), with a concentrated focus on the sociability quality, was developed, for testing the proposed theoretical model of this study. Further, for empirical part of this study, a variance based PLS-SEM statistical approach was employed. More details, regarding the recruitment of participants, research setting and data analysis, are presented in the upcoming sections.

\section{Participants}

Data was collected from students who have been actively involved in a collaborative learning project, using a WBCLIS (i.e. the Co-Reflective) system. Right selection of participants and correct sample size, is necessary, to determine the sanctity of an exploratory study (Farooq and Salam 2020; Hair et al. 2014, Hair et al., 2017). In this context, Barclay et al. (1995) have proposed the use of "10 times rule" as a basic guideline, for determining a minimum sample size, required for a PLS-SEM analysis. According to Hair et al. (2017:20) "minimum sample size should be 10 times the maximum number of arrowheads pointing at a latent variable anywhere in the PLS path model" (Hair et al. 2017:20). The proposed theoretical model of this study (see Fig. 1) includes seven constructs (i.e. four independent, two second order dependent and one third order dependent variable), and maximum four arrowheads are pointing towards system use and user satisfaction. Therefore, based on the aforementioned 10 times rule, minimum sample size for this study, should be 40 respondents. In view of the exploratory nature, and experimental design of 
this study, all 120 students, who were enrolled in the service learning course, and had worked on a collaborative project, using WBCLIS, were considered as potential participants of this study.

\section{Research setting}

This experimental research has been conducted in a service learning course, at a public sector university in Malaysia, using a newly developed WBCLIS, named as the Co-Reflective. As part of their service learning course, students were divided in small groups (i.e. 3 to 5 students in each group), to perform their service learning project (i.e. involving collaboration with students and teachers), at different locations. Being a web-based system, the Co-Reflective was accessible to all users (i.e. teachers and students etc.), all the time and without any constraints of their geographical location. Through the use of WBCLIS, students could perform their service learning project-related assignments, while taking lessons, as per their own convenience. Users were able to operate this WBCLIS, on their mobile devices and laptops, after a simple login / registration process, via any web-browser (e.g. Google Chrome and Internet Explorer etc.). WBCLIS enabled students to collaborate, during their service learning project. Service learning is a kind of experiential learning, in which real life problem based projects are assigned to students, working in collaboration with their teachers (Salam 2020; Salam et al. 2019a).

As part of their service learning class project, students were required to perform their collaborative learning assignments, using the platform of WBCLIS. Moreover, reporting their collaborative efforts for group assignments, and recording their participation in group reflection, through WBCLIS, after every field visit on the service site, was also a part of their service learning project. Therefore, in order to complete their group based service learning project, students were committed to work in collaboration with their teachers. WBCLIS offered a separate interface for teachers, where teachers could design different collaborative assignments, for assessing students' in-group collaboration, learning outcomes and overall group reflection. Students used this WBCLIS, throughout their whole semester, as a part of their service learning group project. At the end of the semester, students were voluntarily invited, to participate in this study, by completing an online selfadministered survey based questionnaire, designed for assessing the sociability quality of WBCLIS. Details regarding the preparation of questionnaire, and data collection process, are presented in the next section.

\section{Questionnaire design, pilot study and data collection}

As mentioned earlier, after the use of WBCLIS (i.e. the Co-Reflective) for whole semester, students were invited, with their informed prior consent, to voluntarily participate, in a self-administered online questionnaire based survey. An online questionnaire was particularly designed, to measure all the constructs involved in the proposed theoretical model of this study (see Fig. 1). The survey instrument comprised of 48 items, used to measure all seven constructs "i.e. system quality, information quality, service quality, sociability quality, user satisfaction, system use and net benefits", of the proposed theoretical model. In order to finalize the items involved in the survey instrument, various 
relevant studies (e.g. Balaban et al. 2013; Brown et al. 2010; DeLone and McLean 2003; Kreijns et al. 2007; Martins et al. 2018; Mohammadi 2015), were consulted thoroughly, for ensuring the validity and reliability of this study. More precisely, a nine items scale was adapted from relevant previous studies (e.g. Balaban et al. 2013; DeLone and McLean 2003; Mohammadi 2015), for assessing system quality. Further, five items scale was adapted from Martins et al. (2018), Balaban et al. (2013), and DeLone and McLean (2003) for measuring information quality, of the under study WBCLIS.

Furthermore, service quality was assessed with a five items scale, adapted from Balaban et al. (2013), DeLone and McLean (2003), and Wang and Liao (2008). Likewise, an eight items scale was adapted from previously published, sociability related studies (e.g. Gao et al. 2010; Junglas et al. 2013; Kreijns et al. 2007; Yamada et al. 2016), for assessing the newly proposed construct of sociability quality. Further, a four items scale was adapted from Alzahrani et al. (2017) and Balaban et al. (2013) for evaluating the system use. Similarly, another four items scale, was borrowed from Balaban et al. (2013) and DeLone and McLean (2003) for assessing user satisfaction. Moreover, acknowledging this fact, that net benefits are case sensitive and they depend on the domain, nature, and characteristics of an information system, a single item scale, is inadequate, for assessing all the facets, of a particular information system (Gress et al. 2010; Martins et al. 2019; Rehak 2020; Salam 2020). Therefore, various levels, contexts, sub-categories and referred system features, were also deliberately considered, while measuring the net benefits of a WBCLIS in this study. Finally, a thirteen items comprehensive scale was adapted, from previous relevant studies (e.g. Balaban et al. 2013; Martins et al. 2018; Wang and Wang 2009), for measuring the perceived net benefits, derived from the use of WBCLIS. Complete list of measurement items, used in this study, is attached in Table 7 in Appendix.

A seven points, Likert type scale was used, to record the responses from all participants. Furthermore, in addition to the aforementioned 48 items, two more questions were also added, in the final questionnaire, for recording the demographic attributes (i.e. gender and age), of all participants. Moreover, before final data collection, a pilot study was also conducted, with a random sample of 10 students (i.e. selected from students' enrolment list), from service learning course. Based on the results of that pilot study, it was found that, all measurement scales, used in this study, have an acceptable level of composite reliability and Cronbach alpha. After establishing the reliability and validity of all measurement scales, (i.e. through pilot study) final data collection started with a convenience sampling approach. As mentioned earlier, all 120 students, enrolled in the service learning class, were considered as potential participants of this study. Therefore, all 120 students, were invited to participate in the final data collection. At the end of survey completion deadline, total 95 responses were recorded; however, 15 inappropriate / incomplete responses were discarded, and only 80 complete responses, were used for final data analysis. Hence, a $66.6 \%$ response rate was recorded, which adds to the parsimony of this study.

\section{Data analysis}

In this study, partial least square based structural equation modelling (PLS-SEM) statistical approach was applied, to assess the explanatory and predictive power of the 
proposed theoretical model. Data analysis was performed, using latest available version 3.2.7 of the SmartPLS software. The PLS-SEM method is suitable, when one cannot guarantee the normality of data (Chin 2010; Hair et al. 2014). Further, choice of PLSSEM approach, was also motivated by it's ability to work with the formative variables, in exploratory studies, even with small sample size (Hair et al., 2011; Henseler et al., 2016). Particularly, in this study, PLS-SEM based statistical approach, was used for two major reasons, i.e. (1) data collected for this study is not normally distributed (Hair et al. 2014; Henseler et al. 2016), and (2) proposed theoretical model is exploratory in nature, and is still in the development phase (Chin 1998; Haque et al., 2009; Shanmugapriya and Subramanian 2015). Demographic information revealed that, $87.7 \%$ of our participants, were between the age group of 20-25 years. Moreover, it was found that, $56.8 \%$ of our participants, were female and $43.2 \%$ were male. Further, results derived from the data analysis of this study, are described in next section.

\section{Results}

Considering the best practices for implementing PLS-SEM, results were thoroughly assessed, for evaluating the measurement models, along with structural model, involved in the proposed theoretical model of this study. Measurement model refers to the scales, used to measure the underlying constructs (Hair et al. 2014). However, structural model, refers to the inner part of the proposed theoretical model (Hair et al. 2014). Observing the guidelines suggested by Hair et al. (2014), results derived from the data analysis, are categorized in following two sections, i.e. (1) evaluation of measurement models (i.e. aimed to assess the reliability and validity of our measurement models), and (2) evaluation of structural model (i.e. aimed to assess the significance of our proposed research hypotheses, along with explanatory and predictive power, of the proposed theoretical model). Now, following subsections present these results, starting with an exhaustive assessment of the measurement models, followed by a full-scale assessment of the structural model.

\section{Evaluation of measurement models}

Evaluation of measurement models begins with the assessment of constructs' reliability and validity (Hair et al. 2014). Table 1 presents the results, of constructs' reliability and validity. As per the guidelines of Henseler et al. (2009), and as an indicator of reliability, items' loading values, should be greater than 0.70 threshold. As depicted in the Table 1, all items in this study, have a greater than 0.70 loading value, except for three items (i.e. SRQ_5, NB_5 and NB_9). Although, these aforesaid items, obtained a loading value, which is less than 0.70 threshold. However, removal of these items (i.e. SRQ_5, NB_5 and NB_9), with lower loading values, did not had a major influence on the overall reliability. Therefore, observing the suggestions of Hair et al. (2014), no items were eliminated from the measurement models. Moreover, as shown in the Table 1, all Cronbach alpha values and composite reliability values, are well above the threshold level, which is another indication of reliability of our measurement models (Hair et al. 2014; Henseler et al. 2009). Hence, overall these results, shown in the Table 1, have confirmed that, all 
Table 1 Results of Measurement Model, Construct Reliability and Validity

\begin{tabular}{|c|c|c|c|c|c|}
\hline Constructs & Items & Loadings & Cronbach's Alpha & Composite Reliability & $\begin{array}{l}\text { Average Variance } \\
\text { Extracted (AVE) }\end{array}$ \\
\hline \multirow[t]{9}{*}{ System Quality } & SQ_1 & 0.832 & \multirow[t]{9}{*}{0.928} & \multirow[t]{9}{*}{0.940} & \multirow[t]{9}{*}{0.634} \\
\hline & SQ_2 & 0.824 & & & \\
\hline & SQ_3 & 0.814 & & & \\
\hline & SQ_4 & 0.728 & & & \\
\hline & SQ_5 & 0.829 & & & \\
\hline & SQ_6 & 0.820 & & & \\
\hline & SQ_7 & 0.779 & & & \\
\hline & SQ_8 & 0.801 & & & \\
\hline & SQ_9 & 0.731 & & & \\
\hline \multirow[t]{5}{*}{ Information Quality } & IQ_1 & 0.795 & \multirow[t]{5}{*}{0.884} & \multirow[t]{5}{*}{0.915} & \multirow[t]{5}{*}{0.683} \\
\hline & IQ_2 & 0.828 & & & \\
\hline & IQ_3 & 0.839 & & & \\
\hline & IQ_4 & 0.822 & & & \\
\hline & IQ_5 & 0.848 & & & \\
\hline \multirow[t]{5}{*}{ Service Quality } & SRQ_1 & 0.784 & \multirow[t]{5}{*}{0.855} & \multirow[t]{5}{*}{0.894} & \multirow[t]{5}{*}{0.631} \\
\hline & SRQ_2 & 0.816 & & & \\
\hline & SRQ_3 & 0.882 & & & \\
\hline & SRQ_4 & 0.869 & & & \\
\hline & SRQ_5 & 0.583 & & & \\
\hline \multirow[t]{8}{*}{ Sociability Quality } & SOQ_1 & 0.791 & \multirow[t]{8}{*}{0.926} & \multirow[t]{8}{*}{0.939} & \multirow[t]{8}{*}{0.660} \\
\hline & SOQ_2 & 0.860 & & & \\
\hline & SOQ_3 & 0.823 & & & \\
\hline & SOQ_4 & 0.835 & & & \\
\hline & SOQ_5 & 0.795 & & & \\
\hline & SOQ_6 & 0.809 & & & \\
\hline & SOQ_7 & 0.842 & & & \\
\hline & SOQ_8 & 0.736 & & & \\
\hline \multirow[t]{4}{*}{ System Use } & SU_1 & 0.809 & \multirow[t]{4}{*}{0.886} & \multirow[t]{4}{*}{0.921} & \multirow[t]{4}{*}{0.746} \\
\hline & SU_2 & 0.826 & & & \\
\hline & SU_3 & 0.932 & & & \\
\hline & SU_4 & 0.883 & & & \\
\hline \multirow[t]{4}{*}{ User Satisfaction } & US_1 & 0.853 & \multirow[t]{4}{*}{0.892} & \multirow[t]{4}{*}{0.925} & \multirow[t]{4}{*}{0.755} \\
\hline & US_2 & 0.885 & & & \\
\hline & US_3 & 0.889 & & & \\
\hline & US_4 & 0.849 & & & \\
\hline Net Benefits & NB_1 & 0.833 & 0.943 & 0.951 & 0.637 \\
\hline & NB_2 & 0.840 & & & \\
\hline & NB_3 & 0.815 & & & \\
\hline & NB_4 & 0.813 & & & \\
\hline & NB_5 & 0.655 & & & \\
\hline & NB_6 & 0.770 & & & \\
\hline & NB_7 & 0.763 & & & \\
\hline & NB_8 & 0.758 & & & \\
\hline
\end{tabular}


Table 1 Results of Measurement Model, Construct Reliability and Validity (Continued)

\begin{tabular}{|c|c|c|c|c|c|}
\hline Constructs & Items & Loadings & Cronbach's Alpha & Composite Reliability & $\begin{array}{l}\text { Average Variance } \\
\text { Extracted (AVE) }\end{array}$ \\
\hline & NB_9 & 0.641 & & & \\
\hline & NB_10 & 0.825 & & & \\
\hline & NB_11 & 0.783 & & & \\
\hline & NB_12 & 0.787 & & & \\
\hline & NB_13 & 0.783 & & & \\
\hline
\end{tabular}

items involved, in the measurement instrument of this study, have a good reliability.

Further, various other tests were also performed, to assess the validity of all measurement models. Average variance extracted (AVE) is commonly used, for the assessment of convergent validity (Hair et al. 2014). As presented in the Table 1, all AVE values are greater than 0.50 threshold (i.e. ranging between 0.631 to 0.755 ), which shows that, the variance of all constructs, is larger than the variation triggered by the individual measurement errors (Hair et al. 2014; Segars 1997). Hence, these results confirm that, all measurement models have an acceptable level of convergent validity (Hair et al. 2011).

Further, various tests (i.e. cross loading values, Fornell and Larcker criterion, and Heterotrait-Monotrait ratio analysis) for checking the discriminant validity, of measurement models, were also performed. Meeting the criterion of cross loading, Table 2 shows that, all loading values, are greater, than their corresponding cross loadings, on other constructs. Conditions of Fornell and Larcker's (1981) criterion are also met, as depicted in the Table 3, all correlation values, between the constructs, are less than the square root values, of their estimated average variance extracted (AVE). Further, results presented in the Table 4 have also fulfilled the conditions of Heterotrait-Monotrait (HTMT) ratio analysis. As depicted in the Table 4 all HTMT values, are less than 0.9 threshold (Henseler et al., 2015). These results have confirmed the discriminant validity, of all measurement models. Overall, results presented in this section, have thoroughly evaluated the measurement models. Results of measurement models assessment have revealed that, all measurement models are reliable and valid. After the assessment of measurement models, this study continues with the analysis of structural model. In order to assess the significance of proposed hypothetical relations, next section presents the results of structural model.

\section{Evaluation of structural model}

In order to evaluate the structural model, first of all multicollinearity of all constructs was tested, by variance inflation factor (VIF) criterion. Results confirmed that, all VIF values range between 1.043 to 2.948 , and are well below, than the threshold value of 5, as suggested by Hair et al. (2014:126, 2017). These results have established the absence of multicollinearity, in the proposed structural model (Hair et al. 2014, Hair et al., 2017). After assessing the proposed structural model, for potential multicollinearity, it was thoroughly assessed for path coefficient values 


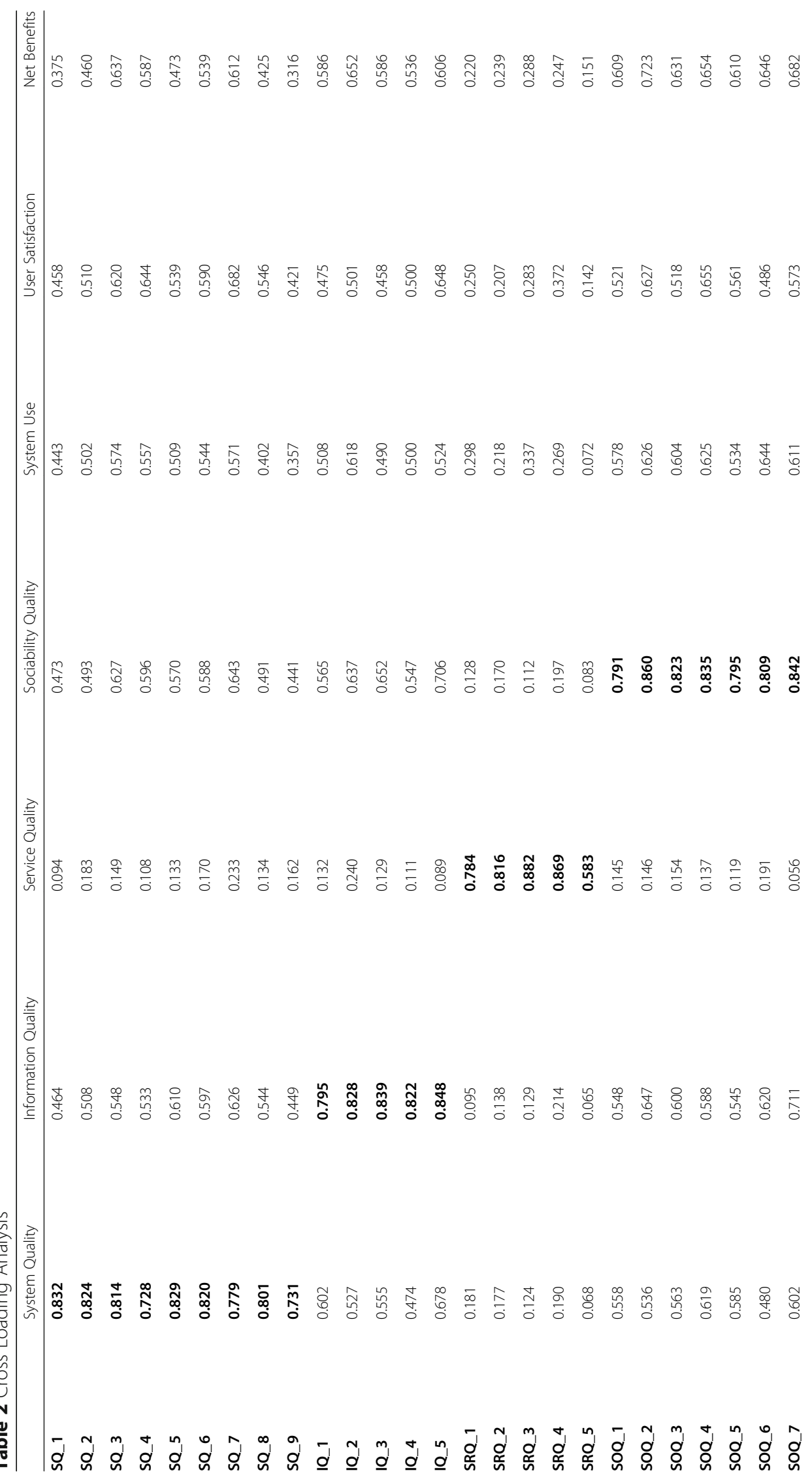




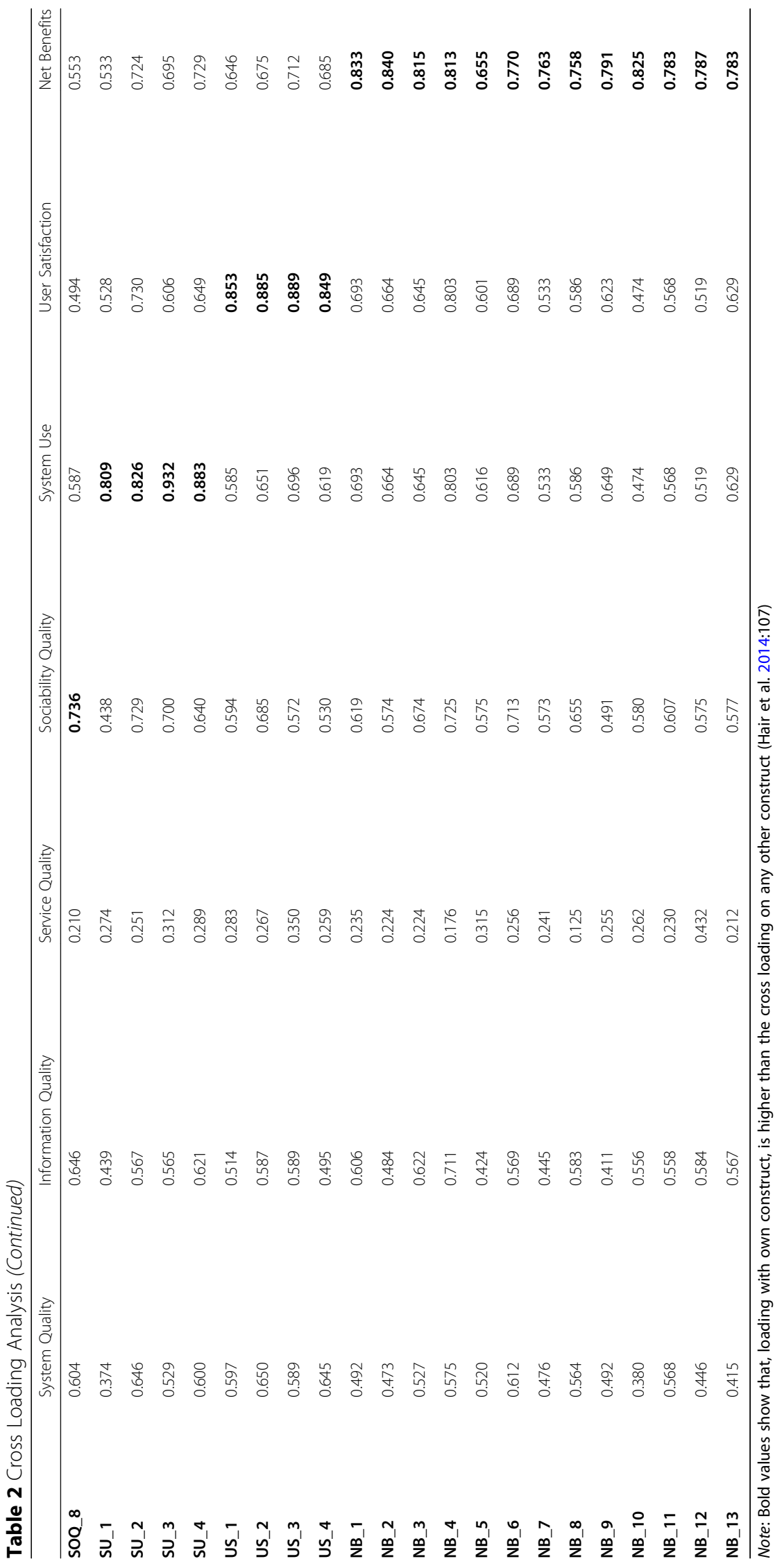


Table 3 Fornell-Larcker Criterion

\begin{tabular}{|c|c|c|c|c|c|c|c|}
\hline Constructs & $\begin{array}{l}\text { System } \\
\text { Quality }\end{array}$ & $\begin{array}{l}\text { Information } \\
\text { Quality }\end{array}$ & $\begin{array}{l}\text { Service } \\
\text { Quality }\end{array}$ & $\begin{array}{l}\text { Sociability } \\
\text { Quality }\end{array}$ & $\begin{array}{l}\text { System } \\
\text { Use }\end{array}$ & $\begin{array}{l}\text { User } \\
\text { Satisfaction }\end{array}$ & $\begin{array}{l}\text { Net } \\
\text { Benefits }\end{array}$ \\
\hline System Quality & 0.796 & & & & & & \\
\hline $\begin{array}{l}\text { Information } \\
\text { Quality }\end{array}$ & 0.689 & 0.826 & & & & & \\
\hline Service Quality & 0.193 & 0.170 & 0.794 & & & & \\
\hline $\begin{array}{l}\text { Sociability } \\
\text { Quality }\end{array}$ & 0.699 & 0.755 & 0.177 & 0.812 & & & \\
\hline System Use & 0.635 & 0.642 & 0.325 & 0.741 & 0.864 & & \\
\hline $\begin{array}{l}\text { User } \\
\text { Satisfaction }\end{array}$ & 0.714 & 0.630 & 0.334 & 0.685 & 0.735 & 0.869 & \\
\hline Net Benefits & 0.636 & 0.720 & 0.295 & 0.788 & 0.786 & 0.783 & 0.798 \\
\hline
\end{tabular}

Note: Values in bold are the square roots of average variance extracted (AVE)

(i.e. $\beta$ values), significance of relationships (i.e. $t$-values) between constructs, along with it's explanatory power (i.e. $\mathrm{R}^{2}$ values). For this purpose, PLS algorithm was performed, followed by a bootstrapping procedure. Observing the suggestions of Hair et al. (2014, 2017), bootstrapping process was executed with 5000 resamples, to measure the significance of path coefficient values. The results of structural model are described in the Fig. 2, and Table 5.

As depicted in the Fig. 2, proposed theoretical model, explains a substantial variation, in the dependent endogenous constructs of this study. More precisely, with a $70.9 \%$ explanatory power (i.e. $\mathrm{R}^{2}=0.709$ ) for net benefits, followed by $66.2 \%$ explanatory power (i.e. $\mathrm{R}^{2}=0.662$ ) for system use, and $61.5 \%$ explanatory power (i.e. $\left.R^{2}=0.615\right)$ for user satisfaction towards WBCLIS, this proposed structural model, has evidently advanced the DeLone and McLean's (2003) updated IS success model. Further, results of path coefficients and bootstrapping procedure, have confirmed that, most of the hypotheses in the proposed structural model were supported, except for H1a, H2a, H2b and H3a. Since, majority of the proposed hypotheses are significant, and endogenous constructs have a high explanatory power; therefore, we suggest that, proposed theoretical model has imparted substantial theoretical contribution, by assessing the construct of sociability quality, along with other existing dimensions of the DeLone and McLean's (2003) updated IS success model.

As depicted in the Table 5, endogenous construct 'system use' is significantly ex-

Table 4 Heterotrait-Monotrait (HTMT)

\begin{tabular}{|c|c|c|c|c|c|c|c|}
\hline Constructs & $\begin{array}{l}\text { System } \\
\text { Quality }\end{array}$ & $\begin{array}{l}\text { Information } \\
\text { Quality }\end{array}$ & Service Quality & $\begin{array}{l}\text { Sociability } \\
\text { Quality }\end{array}$ & System Use & $\begin{array}{l}\text { User } \\
\text { Satisfaction }\end{array}$ & $\begin{array}{l}\text { Net } \\
\text { Benefits }\end{array}$ \\
\hline System Quality & - & & & & & & \\
\hline Information Quality & 0.748 & - & & & & & \\
\hline Service Quality & 0.210 & 0.186 & - & & & & \\
\hline Sociability Quality & 0.742 & 0.832 & 0.207 & - & & & \\
\hline System Use & 0.672 & 0.714 & 0.345 & 0.802 & - & & \\
\hline User Satisfaction & 0.769 & 0.703 & 0.360 & 0.751 & 0.817 & - & \\
\hline Net Benefits & 0.653 & 0.783 & 0.328 & 0.837 & 0.837 & 0.847 & - \\
\hline
\end{tabular}




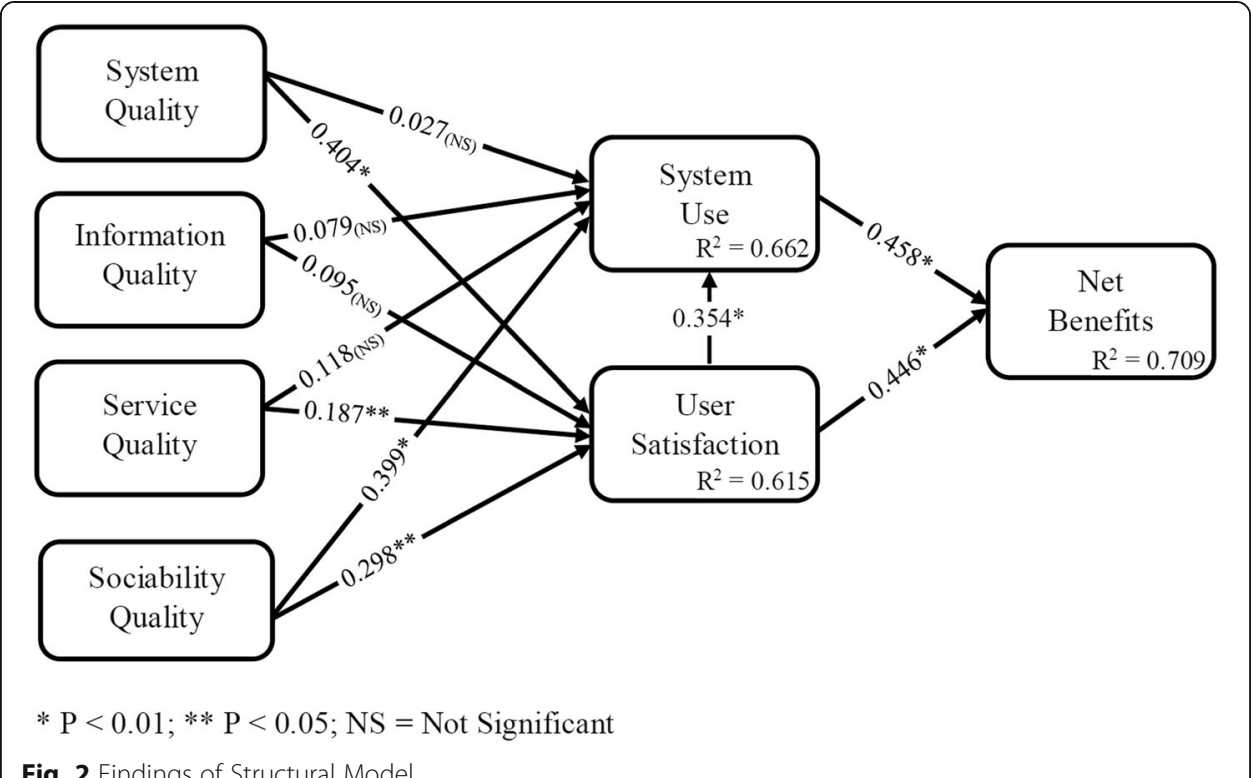

Fig. 2 Findings of Structural Model

plained by sociability quality $(\beta=0.399, t$-value $=3.368, p<0.01)$ and user satisfaction $(\beta=0.354, t$-value $=2.709, p<0.01)$, consequently confirming that H4a and H5 are significant. Moreover, endogenous construct 'user satisfaction' is significantly explained by system quality $(\beta=0.404, t$-value $=3.353, p<0.01)$, service quality $(\beta=0.187, t$-value $=$ 2.350, $p<0.05)$, and sociability quality $(\beta=0.298, t$-value $=2.211, p<0.05)$, thus H1b, $\mathrm{H} 3 \mathrm{~b}$ and $\mathrm{H} 4 \mathrm{~b}$ are also supported. Further, as shown in the Fig. 2, proposed theoretical model, explains $70.9 \%$ variation (i.e. $R^{2}=0.709$ ) in the third order endogenous construct, i.e. 'net benefits', where both, user satisfaction $(\beta=0.446, t$-value $=4.651, p<$ $0.01)$ and system use $(\beta=0.458, t$-value $=4.640, p<0.01)$ have a significant impact, on the net benefits derived from WBCLIS. Hence, $\mathrm{H} 6$ and $\mathrm{H} 7$ are also supported.

Table 5 Hypotheses Assessment

\begin{tabular}{|c|c|c|c|c|c|c|}
\hline \multicolumn{2}{|c|}{ Hypotheses } & \multirow{2}{*}{$\frac{\boldsymbol{\beta}}{0.027 \text { (NS) }}$} & \multirow{2}{*}{$\frac{\boldsymbol{t} \text {-Value }}{0.200}$} & \multirow{2}{*}{$\frac{\boldsymbol{p} \text {-Value }}{0.841}$} & \multirow{2}{*}{$\begin{array}{l}\text { Decision } \\
\text { Not supported }\end{array}$} & \multirow{2}{*}{$\frac{\text { Effect size } \boldsymbol{f}^{\mathbf{2}}}{0.001}$} \\
\hline H1a & System quality $\rightarrow$ system use & & & & & \\
\hline H1b & System quality $\rightarrow$ user satisfaction & $0.404^{*}$ & 3.353 & 0.001 & Supported & 0.189 medium \\
\hline $\mathrm{H} 2 \mathrm{a}$ & Information quality $\rightarrow$ system use & 0.079 (NS) & 0.742 & 0.458 & Not supported & 0.007 \\
\hline $\mathrm{H} 2 \mathrm{~b}$ & Information quality $\rightarrow$ user satisfaction & 0.095 (NS) & 0.924 & 0.356 & Not supported & 0.009 \\
\hline H3a & Service quality $\rightarrow$ system use & 0.118 (NS) & 1.555 & 0.120 & Not supported & $0.036^{\text {small }}$ \\
\hline $\mathrm{H} 3 \mathrm{~b}$ & Service quality $\rightarrow$ user satisfaction & $0.187^{* *}$ & 2.350 & 0.019 & Supported & $0.087^{\text {small }}$ \\
\hline $\mathrm{H} 4 \mathrm{a}$ & Sociability quality $\rightarrow$ system use & $0.399^{*}$ & 3.368 & 0.001 & Supported & 0.160 medium \\
\hline $\mathrm{H} 4 \mathrm{~b}$ & Sociability quality $\rightarrow$ user satisfaction & $0.298^{* *}$ & 2.211 & 0.027 & Supported & $0.085^{\text {small }}$ \\
\hline H5 & User satisfaction $\rightarrow$ system use & $0.354^{*}$ & 2.709 & 0.007 & Supported & $0.143^{\text {small }}$ \\
\hline H6 & User satisfaction $\rightarrow$ net benefits & $0.446^{*}$ & 4.651 & 0.000 & Supported & 0.313 medium \\
\hline H7 & System use $\rightarrow$ net benefits & $0.458^{*}$ & 4.640 & 0.000 & Supported & 0.330 medium \\
\hline
\end{tabular}

Note: Critical $t$-values ${ }^{*} 2.58(P<0.01) ; * * 1.96(P<0.05)$; NS = Not Significance (Hair et al. 2014:138);

Cohen's (1988) effect size $f^{2} \geq 0.350=$ large effect size, $f^{2} \geq 0.150=$ medium effect size, $f^{2} \geq 0.02=$ small effect size (Hair et al. 2014:178) 
In addition to the aforementioned assessment, predictive relevance of the proposed theoretical model was also evaluated, by employing Stone (1974) and Geisser's (1974) $\mathrm{Q}^{2}$ test. As per rule of thumb, a higher $\mathrm{Q}^{2}$ value, indicates higher predictive relevance, of a proposed theoretical model (Chin 2010; Henseler et al. 2009). The results confirm that, $Q^{2}$ values of all endogenous constructs, were greater than zero. Starting with system use $\left(Q^{2}=0.445\right)$, followed by, user satisfaction $\left(Q^{2}=0.417\right)$, and net benefits $\left(Q^{2}=\right.$ 0.405), all $\mathrm{Q}^{2}$ values indicate that, proposed theoretical model has a good predictive relevance, for assessing WBCLIS, for it's sociability quality and other success dimensions of an information system.

Finally, after determining the explanatory power and predictive relevance, overall model fit is evaluated using Goodness of Fit $\left(\mathrm{GoF}=\left(\sqrt{ }\left(\mathrm{AVE} \times \mathrm{R}^{2}\right)\right)\right)$ criterion, proposed by Tenenhaus et al. (2005). According to Wetzels et al. (2009) and Henseler et al. (2016), a high GoF value shows that, proposed theoretical model is parsimonious. Based on the guideline of Tenenhaus et al. (2005), Wetzels et al. (2009) and Henseler et al. (2016), GoF calculation for our proposed theoretical model is presented in the Table 6 . The results have confirmed that, proposed theoretical model has obtained a substantial $\mathrm{GoF}_{\text {large }}$ value of 0.6699 , which shows a good model fit.

\section{Discussion}

As mentioned earlier, most of the hypotheses in the proposed theoretical model are significant, except for H1a, H2a, H2b and H3a (see Table 5). Based on the statistical results, it is found that, the system use of WBCLIS is explained by sociability quality and perceived user satisfaction. Moreover, it is found that, social functionalities, which are represented by sociability quality of a CSCL system, are also crucial success factor for an information system. By investigating the link between sociability aspect and system use, upshots of this study, have also verified the outcomes reported by Junglas et al. (2013) and Gao et al. (2010), who initially proposed the connection, between sociability and system use. Further, with respect to the system quality, H1a was not significant, which shows that, the use of WBCLIS is not largely influenced by system quality. However, contrary to this, Mohammadi (2015) has reported that, technical system quality has an indirect positive impact, on actual system use. Further, Mohammadi (2015) has also

Table 6 Goodness of Fit (GoF) Index

\begin{tabular}{|c|c|c|}
\hline Constructs & AVE & $R^{2}$ \\
\hline System Quality & 0.634 & \\
\hline Information Quality & 0.683 & \\
\hline Service Quality & 0.631 & \\
\hline Sociability Quality & 0.660 & \\
\hline System Use & 0.746 & 0.662 \\
\hline User Satisfaction & 0.755 & 0.615 \\
\hline Net Benefits & 0.637 & 0.709 \\
\hline Average Score & 0.6780 & 0.6620 \\
\hline$A V E^{*} R^{2}$ & 0.4488 & \\
\hline GoF $=\sqrt{ }\left(A V E \times R^{2}\right)$ & 0.6699 & \\
\hline
\end{tabular}


reported a direct and positive connection, between system quality and users' intention to use an e-learning system. Further, H1b shows that, the system quality has a significant influence on user satisfaction.

Similar results regarding system quality and user satisfaction, have been reported by various preceding studies (e.g. Aparicio et al. 2017; Cidral et al. 2018; Costa et al. 2016; Hassanzadeh et al. 2012) on the success of e-learning information systems. Therefore, outcomes of this study put forward that, if a WBCLIS has a high system quality, it can enhance users' overall satisfaction, derived from the system use. Another important success factor is information quality, which is found nonsignificant, in the case of WBCLIS; results indicate that, information quality (see $\mathrm{H} 2 \mathrm{a}$ and $\mathrm{H} 2 \mathrm{~b}$ ) has no major influence on system use and user satisfaction. These outcomes are consonant and inline with the findings of Balaban et al. (2013), as they also reported that, information quality has a non-significant impact on system use and user satisfaction. However, these findings of $\mathrm{H} 2 \mathrm{a}$ and $\mathrm{H} 2 \mathrm{~b}$ are contrary to Cidral et al. (2018), as they reported a statistically significant impact of information quality, on system use and perceived user satisfaction, towards an e-learning information system. It is important to note that, Cidral et al. (2018) conducted their study in the Brazilian context only; therefore, this contradiction of results, can be because of difference in the cultural background and origin of respondents, making it an entirely different sample.

Moreover, it is vital to note that, in this study, participants were undergraduate students, enrolled in a project based service learning course, at a public sector university in Malaysia; therefore, all respondents of this study had a similar period of experience on WBCLIS. Whereas, in other studies (e.g., Cidral et al. 2018; Martins et al. 2018) respondents were recruited, from various different levels and programs, making their sample a blend of respondents, having a varying period of experience. In addition, this study argues that, maturity of information system, also effects system use and user satisfaction. Studies, which have reported contradictory findings (e.g., Cidral et al. 2018; Martins et al. 2018), were conducted on very established and mature CSCL systems. However, in our case, this study was conducted on the success factors, of a newly developed / pre-mature WBCLIS (i.e. the Co-Reflective). Further, findings regarding a non-significant relationship, among service quality and system use (see H3a), have validated similar results, reported by some other studies (e.g., Aparicio et al. 2017; Cidral et al. 2018; Hassanzadeh et al. 2012; Tam and Oliveira 2016); however, these findings are contrary to the results reported by Martins et al. (2018).

Reporting a statistically significant relationship among service quality and system use, Martins et al. (2018) have argued that, if students experience any problem, while using education management information systems, access to online support and good service quality can motivate them towards system use; however, poor service quality may adversely affect, students' intention to use an education management information system. Furthermore, results of H3b has confirmed that, service quality has a direct and significant impact on user satisfaction. Thus, the notion that, service quality leads to a higher user satisfaction towards WBCLIS, is also strengthened (Aldholay et al. 2018; Alzahrani et al. 2017; Mukred and Yusof 2018). Further, it is found that, sociability quality positively influences system use (see 
H4a) and user satisfaction (see H4b). As a unique contribution of the findings of this study, sociability quality of WBCLIS, has emerged as an important success factor. Therefore, this study argues that, if a CSCL system provides effective and flexible social functionalities, then these functionalities, will not only enhance the quality of it's collaborative learning, but they will also add up, to the overall increase in user satisfaction and system use. For that reason, outcomes of this study put forward that, sociability, as it is reported by prior studies (e.g., Gao et al. 2010; Junglas et al. 2013) is not enough; rather, high 'sociability quality' is what makes a WBCLIS more successful.

Moreover, results have also confirmed that, user satisfaction has a direct and statistically significant influence on system use (see H5). Similar results were reported by Martins et al. (2018), regarding the use of education management information systems. Further, these results have validated the findings of Aparicio et al. (2016) and Mohammadi (2015), concerning the use of e-learning systems. Furthermore, findings of this study have established that, ultimately success of an information system is determined, with the net benefits, derived by its' users (DeLone and McLean 2003). Therefore, as a determinant of success of WBCLIS, it's net benefits for all users, were deeply analyzed. Results confirmed that, user satisfaction and system use, both hold a significantly cogent sway on the net benefits (see H6 and H7) of WBCLIS. Therefore, it is suggested that, user satisfaction and system use, can play a crucial part, in defining the success of an academic / education related information system (Balaban et al. 2013; Martins et al. 2018). Specifically, in the context of WBCLIS, if students are satisfied with the features and functionalities, offered by that particular system, then their performance, in collaborative learning activities will be enhanced; thereby, maximizing their learning outcomes and adding to the net benefits of WBCLIS.

\section{Theoretical contribution and practical implications}

This study has proposed and validated a theoretical model, for assessing the sociability quality of WBCLIS. The concept of 'Sociability quality' is proposed as a new success dimension, in the DeLone and McLean's (2003) updated IS success model. A significant theoretical contribution is imparted, by extending the DeLone and McLean's (2003) updated IS success model. Moreover, aforementioned discussion on the sociability aspects, in the findings of this study, has also enhanced our understanding, regarding social interaction theory (Gunawardena 1995; Kreijns et al. 2007; Mills et al. 2010). Findings of this study have established that, sociability quality is an imperative factor, for predicting the success of a CSCL system, and it has a salutary and favourable impact on system use and user satisfaction. Furthermore, results also confirm that, user satisfaction and system use are interdependent, and both have a favourable, positive influence on the net benefits of a WBCLIS. Further, detailed analysis of the proposed hypotheses has confirmed that, system quality, service quality and sociability quality, significantly explain the user satisfaction towards WBCLIS. Moreover, it is found that, sociability quality and user satisfaction, are significant drivers of system use, in the context of WBCLIS.

While incorporating a relatively new concept of 'sociability quality', proposed theoretical model has demonstrated a notable explanatory power, for assessing the net benefits of WBCLIS. Moreover, outcomes of this study, offer a noteworthy contextual contribution, 
by validating the success of a WBCLIS, using proposed theoretical model of this study, in the context of service learning based collaborative project performance. In addition, findings of this study, offer a number of practical contributions for designers / developers of CSCL systems and higher education institutions. As described previously, this study was conducted on the implementation, of a newly developed WBCLIS (i.e. the Co-Reflective). This WBCLIS enabled teachers, to design collaborative learning activities, in which students could work, in collaboration with their fellow students. The successful implementation of WBCLIS, can facilitate students to act as a team, share information, practice collaborative critical reflection, which is not otherwise possible in the traditional classroom settings. Moreover, it is suggested that, the use of WBCLIS can encourage students, to share their service learning experiences, exchange ideas, share their personal perspectives, deliberate on others' opinions and choose a suitable solution for their real life problems.

Further, use of WBCLIS is thoroughly described, by the assessment of proposed theoretical model, which has integrated "system quality, information quality, service quality" and sociability quality, in the relationship with system use and user satisfaction, for assessing the net benefits of a WBCLIS. The results indicate that, along with functional qualities of a CSCL system, developers should also focus on the social components of CSCL system, for enhancing user satisfaction, through sociability quality of their system. By focusing on social and technological features of a CSCL system, institutions can be successful, in developing a sound social environment, for collaborative learning and social interaction between teachers and students. Therefore, understanding of sociability quality, is a critical aspect of CSCL system. Further, as another practical contribution of this study, it is suggested that, a CSCL system should allow articulation of collaboration and communication, among teachers and students. Moreover, as mentioned in the results section, sociability quality has a significant salutary impact, on the use of WBCLIS and user satisfaction. Therefore, online collaborative learning environment should be interactive, organized and sociable; so that, students can collaborate with teachers and other fellow students, simultaneously, for on time completion of their collaborative learning tasks.

\section{Limitations and future research directions}

Outcomes of this study have validated the significance of a new IS success dimension (i.e. sociability quality) in the context of WBCLIS. Although, this study contributes well in the advancement of theory, and also opens up various future research directions; yet, some limitations are identified, to serve as future research directions. As stated earlier, this study was aimed to assess 'sociability quality' in the context of WBCLIS; for that reason, this study is not passable to entirely capture all the factors of IS success. Therefore, more studies on new success dimensions, are warranted in future also, to have an exhaustive comprehension, of all IS success dimensions. During this study, it was observed that, existing CSCL systems have downplayed, on the provision of sociability features; therefore, it is suggested that, more sociable WBCLIS should be designed, with advanced technological support, to provide a sociable collaborative learning environment. Further, proposed framework of this study, can be expanded, to validate more novel IS success dimensions, 
in other cultural and contextual settings. Taking new IS success dimensions into consideration, future studies can employ our proposed, sociability quality based IS success model, as their underpinning framework. Moreover, future research work can be performed, to evaluate the proposed theoretical model, with different CSCL systems and with a larger sample size.

\section{Conclusion}

As described formerly, this study is about the sociability quality of WBCLIS. The construct of sociability quality is introduced, as a new success dimension in the DeLone and McLean's (2003) updated IS success model. Considering the experimental nature of this study, a WBCLIS (i.e. the Co-Reflective) was designed, to facilitate teachers and students, with a collaborative learning environment. This WBCLIS was developed in a way, in which teachers and students could interact, collaborate and actively participate, throughout their service learning project. Under study, WBCLIS was aimed to offer, several sociability features, that can facilitate users, throughout their collaborative learning process. For instance, every group of students had a self-regulated reflection environment, which allowed them to update and monitor their daily project progress, share information with their group members, collaborate and reflect on their fieldwork experience. Moreover, WBCLIS also enabled teachers, to monitor students' progress, social behavior and collaboration approach, throughout their service learning project.

As mentioned in the methodology section, this study involved students, who were enrolled in the service learning course. For this purpose, students were divided in small groups, of 3 to 5 students working in each group. As part of their group project, assigned to them, during their service learning course, at a public sector university in Malaysia, students used this WBCLIS, throughout their whole semester, to actively participate, in various collaborative learning activities, such as sharing experiences, and discussing project related issues. At the end of the semester, all students were invited to voluntarily participate in an online self-administered survey based questionnaire, which was designed to assess the 'sociability quality' of WBCLIS, through a proposed theoretical model (see Fig. 1). It is pertinent to mention that, all participants had an equal period of access and uniform experience with WBCLIS, which also adds to the standing of the sample and data used for analyzing the proposed theoretical model of this study.

PLS-SEM based statistical approach was employed, for a thorough assessment of measurement models and structural model of this study. Findings of GoF index has shown that, proposed theoretical model has a good fit. Further, on the base of the findings of this study, it is righteous to suggest that, a WBCLIS should offer a variety of ways, for collaboration and social interaction between users. Easy and flexible features, for interaction between users, and sociability quality of a WBCLIS, contribute much, towards user satisfaction, which in turn leads to a significant growth in the learning outcomes, productivity and performance of all the stakeholders. Therefore, this study confirms that, with good sociability quality, WBCLIS can offer a flexible collaborative platform, to all users, for interacting and interrelating with each other, to design solutions for their real-world problems. Further, empirical validation of proposed theoretical model, in the service learning course, has also confirmed that, the sociability quality of WBCLIS, is a strong determinant and precursor, of the system use and user satisfaction, along with other IS success dimensions. 


\section{Appendix}

Table 7 Measurement Scale Items

Code Items
System Quality Adapted from (Balaban et al. 2013; DeLone and McLean 2003; Mohammadi 2015)
SQ_1 Web-Based Collaborative Learning Information System (WBCLIS) is easy to use.
SQ_2

Service Quality Adapted from (Balaban et al. 2013; DeLone and McLean 2003; Wang and Liao 2008)

SRQ_1 In case of any difficulty in using WBCLIS, I was provided with quick online assistance.

SRQ_2 IT department facilitates me, when I face any difficulty while using WBCLIS.

SRQ_3 WBCLIS is compatible with other technologies I have used.

SRQ_4 A technical staff is available, to provide help for using WBCLIS.

SRQ_5 Teachers are always willing to help, and answer my queries, regarding WBCLIS.

Sociability Quality Adapted from (Gao et al. 2010; Junglas et al. 2013; Kreijns et al. 2007; Yamada et al. 2016)

SOC_1 WBCLIS has enabled me to easily contact with my group members.

SOC_2 WBCLIS provides an excellent communication platform for social interaction.

SOC_3 WBCLIS facilitates the sharing of information and documents with my group members.

SOC_4 The use of WBCLIS, has enabled me, to become a well performing team member of my group.

SOC_5 I feel confident and comfortable, while participating in the collaborative discussions, through WBCLIS.

SOC_6 I can easily communicate my ideas / opinions, using WBCLIS during online collaborative work

SOC_7 WBCLIS facilitates me, in developing healthy working relationships, with my teammates.

SOC_8 WBCLIS also enables us to create a sociable environment, for non-task related conversation.

System Use Adapted from (Alzahrani et al. 2017; Balaban et al. 2013)

SU_1 While using WBCLIS, I use available features for group reflection.

SU_2 In my personal experience, I am very likely to use WBCLIS.

SU_3 While using WBCLIS, I collaborate with my peers and teachers. 
Table 7 Measurement Scale Items (Continued)

\begin{tabular}{ll}
\hline Code & Items \\
\hline SU_4 & I use many functions of WBCLIS, during collaborative learning project. \\
User Satisfaction Adapted from (Balaban et al. 2013; DeLone and McLean 2003) \\
US_1 $\quad$ I find WBCLIS useful for collaborative learning. \\
US_2 & I like working with the WBCLIS. \\
US_3 & The functions provided by WBCLIS, are satisfactory for group reflection. \\
US_4 & Overall, I am pleased with the functionality of WBCLIS. \\
Net Benefits Adapted from (Balaban et al. 2013; Martins et al. 2018; Wang and Wang 2009) \\
NB_1 & WBCLIS inspires me to develop positive attitude for group reflection. \\
NB_2 & WBCLIS involves all students actively, throughout their collaborative learning process. \\
NB_3 & Using WBCLIS aids me, to fulfil collaborative learning outcomes. \\
NB_4 & Using WBCLIS helps me, to make connection between informal (i.e. learning at \\
NB_5 & community service site) and formal (i.e. learning in classrooms) learning experience. \\
NB_6 & My class performance is enhanced by using WBCLIS. \\
NB_7 & Use of WBCLIS promotes critical thinking skills and collaborative knowledge building. \\
NB_8 & Use of WBCLIS leads to increased transparency in collaborative learning process. \\
NB_9 & Use of WBCLIS encourages discussion and negotiation, to develop a shared \\
NB_10 & WBderstanding. \\
NB_11 & I feel competent to collaborate with others using WBCLIS. \\
NB_12 & WBCLIS enables me, to critically analyze my practical experience, for developing new \\
NB_13 & I comprehensions.
\end{tabular}

\section{Acknowledgements}

Authors wish to thank all the anonymous reviewers, for their insightful comments, on the earlier drafts of this manuscript. This manuscript is a part of Ph.D. dissertation of the corresponding author; therefore, she wishes to acknowledge the support and guidance of her supervisors, Dr. Dayang Nurfatimah Awang Iskandar and Dr. Dayang Hanani Abang Ibrahim. Same acknowledgment goes to the editor(s) of the International Journal of Educational Technology in Higher Education, for helping in refining this manuscript, in it's current form. Furthermore, although this study does not explicitly or otherwise refer to / arbitrate the use of the Co-Reflective (i.e. available online at $h t t p: / w w w$. co-reflective.com); yet, as a founder of the Co-Reflective, corresponding author acknowledges a financial interest in the Co-Reflective.

\section{About the authors \\ Maimoona Salam}

Maimoona Salam holds a Ph.D. in Computer Science from the Faculty of Computer Science and Information Technology, Universiti Malaysia Sarawak (UNIMAS), Kota Samarahan, Sarawak, Malaysia. She has published more than 10 peer-reviewed articles, in several highly accredited international journals, including the International Journal of Educational Technology in Higher Education, Asia Pacific Education Review, Telematics and Informatics. She is also founder of the Co-Reflective (i.e. available online at http://www.co-reflective.com). She is interested in post-doctoral fellowship and research collaborations, in the area of technology design and development, for different experiential learning pedagogies (e.g. service learning), technology acceptance, effective technology integration in higher education and advanced computer supported collaborative learning information systems. Maimoona Salam is the corresponding author, and is reachable at: maimoonasalam1@yahoo.com

Muhammad Shoaib Farooq

Muhammad Shoaib Farooq holds a Ph.D. in Entrepreneurship from the Faculty of Economics and Business,

Universiti Malaysia Sarawak (UNIMAS), Kota Samarahan, Sarawak, Malaysia. He has published more than 10 peerreviewed articles. He is also interested in post-doctoral fellowship and research collaborations, in the area of entrepreneurship, business education, hospitality management, CSR and organizational behavior. He is reachable at: sshoaibfarooq2@yahoo.com 


\section{Authors' contributions}

Maimoona Salam prepared the conceptual framing and performed the preliminary analysis. Muhammad Shoaib Farooq undertook the editing and helped in revising this manuscript. Final manuscript is approved by all authors.

\section{Funding}

Not applicable.

\section{Availability of data and materials}

The data used in this study is confidential.

\section{Competing interests}

The authors declare that they have no competing interests.

\section{Author details}

${ }^{1}$ Faculty of Computer Science and Information Technology, Universiti Malaysia Sarawak (UNIMAS), Kota Samarahan, Kuching, Sarawak, Malaysia. ${ }^{2}$ Institute of Business and Management, University of Engineering and Technology, Lahore, Pakistan.

Received: 16 October 2019 Accepted: 4 March 2020

Published online: 08 May 2020

\section{References}

Aldholay, A., Isaac, O., Abdullah, Z., Abdulsalam, R., \& Al-Shibami, A. H. (2018). An extension of Delone and McLean IS success model with self-efficacy: Online learning usage in Yemen. International Journal of Information and Learning Technology, 35(4), 285-304. https://doi.org/10.1108/IILT-11-2017-0116.

Al-Fraihat, D., Joy, M., Masa'deh, R., \& Sinclair, J. (2020). Evaluating E-learning systems success: An empirical study. Computers in Human Behavior, 102, 67-86. https://doi.org/10.1016/j.chb.2019.08.004.

Al-Rahmi, W. M., \& Zeki, A. M. (2017). A model of using social media for collaborative learning to enhance learners' performance on learning. Journal of King Saud University - Computer and Information Sciences, 29(4), 526-535. https://doi. org/10.1016/j.jksuci.2016.09.002.

Al-Samarraie, H., \& Saeed, N. (2018). A systematic review of cloud computing tools for collaborative learning: Opportunities and challenges to the blended-learning environment. Computers \& Education, 124(1), 77-91. https://doi.org/10.1016/j. compedu.2018.05.016.

Al-Samarraie, H., Teng, B. K., Alzahrani, A. I., \& Alalwan, N. (2017). E-learning continuance satisfaction in higher education: A unified perspective from instructors and students. Studies in Higher Education, 43(11), 2003-2019. https://doi.org/10.1080/ 03075079.2017.1298088.

Alzahrani, A. I., Mahmud, I., Ramayah, T., Alfarraj, O., \& Alalwan, N. (2017). Modelling digital library success using the DeLone and McLean information system success model. Journal of Librarianship and Information Science, 51(2), 291-306. https:// doi.org/10.1177/0961000617726123.

Anaya, L. A. (2013). Realizing the Benefits from Enterprise information systems: A Sociomaterial perspective. Procedia Technology, 9, 473-479. https://doi.org/10.1016/.protcy.2013.12.052.

Aparicio, M., Bacao, F., \& Oliveira, T. (2016). An e-learning theoretical framework. Journal of Educational Technology \& Society, 19(1), 292-307 Retrieved from JSTOR.

Aparicio, M., Bacao, F., \& Oliveira, T. (2017). Grit in the path to e-learning success. Computers in Human Behavior, 66(1), 388399. https://doi.org/10.1016/j.chb.2016.10.009.

Apostolou, B., Dorminey, J. W., Hassell, J. M., \& Rebele, J. E. (2014). A summary and analysis of education research in accounting information systems (AIS). Journal of Accounting Education, 32(2), 99-112. https://doi.org/10.1016/j.jaccedu. 2014.02.002.

Arendt, B. (2019). Discourse acquisition in peer talk - The case of argumentation among kindergartners. Learning, Culture and Social Interaction, 23, 100342. https://doi.org/10.1016/j.lcsi.2019.100342.

Aslan, S., \& Hamurcu, H. (2015). The prediction of separation-individuation in Turkish late adolescents through perceived sociability of computer-supported collaborative learning environments. Procedia - Social and Behavioral Sciences, 203, 1115. https://doi.org/10.1016/j.sbspro.2015.08.252.

Atan, H., Rahman, Z. A., Majid, O., \& Dahlan, N. (2012). The web collaborative content Organiser (Webcoco): A conceptual framework for system development. Procedia - Social and Behavioral Sciences, 67, 167-174. https://doi.org/10.1016/j. sbspro.2012.11.317.

Baishya, K., \& Samalia, H. V. (2019). Extending unified theory of acceptance and use of technology with perceived monetary value for smartphone adoption at the bottom of the pyramid. International Journal of Information Management, 102036. https://doi.org/10.1016/j.jijnfomgt.2019.11.004.

Balaban, I., Mu, E., \& Divjak, B. (2013). Development of an electronic portfolio system success model: An information systems approach. Computers \& Education, 60(1), 396-411. https://doi.org/10.1016/j.compedu.2012.06.013.

Barclay, D., Higgins, C., \& Thompson, R. (1995). The partial least squares (PLS) approach to causal modeling: Personal computer adoption and use as an illustration (with commentaries). Technology Studies, 2(2), 285-324.

Bharati, P., \& Berg, D. (2005). Service quality from the other side: Information systems management at Duquesne light. International Journal of Information Management, 25(4), 367-380. https://doi.org/10.1016/j.jijnfomgt.2005.04.008.

Bhuasiri, W., Xaymoungkhoun, O., Zo, H., Rho, J. J., \& Ciganek, A. P. (2012). Critical success factors for e-learning in developing countries: A comparative analysis between ICT experts and faculty. Computers \& Education, 58(2), 843-855. https://doi. org/10.1016/j.compedu.2011.10.010.

Brown, S. A., Dennis, A. R., \& Venkatesh, V. (2010). Predicting collaboration technology use: Integrating technology adoption and collaboration research. Journal of Management Information Systems, 27(2), 9-54. https://doi.org/10.2753/MIS07421222270201. 
Bulotsky-Shearer, R. J., Fernandez, V. A., Bichay-Awadalla, K., Bailey, J., Futterer, J., \& Qi, C. H. (2020). Teacher-child interaction quality moderates social risks associated with problem behavior in preschool classroom contexts. Journal of Applied Developmental Psychology, 67, 101103. https://doi.org/10.1016/j.appdev.2019.101103.

Burdelski, M. (2019). 'Say can I borrow it': Teachers and children managing peer conflict in a Japanese preschool. Linguistics and Education, 100728. https://doi.org/10.1016/j.linged.2019.04.002.

Chan, J. W. W., \& Pow, J. W. C. (2020). The role of social annotation in facilitating collaborative inquiry-based learning Computers \& Education, 147, 103787. https://doi.org/10.1016/j.compedu.2019.103787.

ChanLin, L.-J. (2012). Learning strategies in web-supported collaborative project. Innovations in Education and Teaching International, 49(3), 319-331. https://doi.org/10.1080/14703297.2012.703016.

Chen, H., Park, H. W., \& Breazeal, C. (2020). Teaching and learning with children: Impact of reciprocal peer learning with a social robot on children's learning and emotive engagement. Computers \& Education, 150, 103836. https://doi.org/10. 1016/j.compedu.2020.103836.

Cheung, R., \& Vogel, D. (2013). Predicting user acceptance of collaborative technologies: An extension of the technology acceptance model for e-learning. Computers \& Education, 63(1), 160-175. https://doi.org/10.1016/j.compedu.2012.12.003.

Chin, W. (1998). The partial least squares approach to structural equation modeling. Modern Methods for Business Research, 295(2), 295-336.

Chin, W. W. (2010). How to write up and report PLS analyses. In V. E. Vinzi, W. W. Chin, J. Henseler, \& H. Wang (Eds.), Handbook of partial least squares: Concepts, methods and applications, (pp. 655-690). https://doi.org/10.1007/978-3-54032827-8_29.

Churchill, D. (2011). Web 2.0 in education: A study of the explorative use of blogs with a postgraduate class. Innovations in Education and Teaching International, 48(2), 149-158. https://doi.org/10.1080/14703297.2011.564009.

Cidral, W. A., Oliveira, T., Di Felice, M., \& Aparicio, M. (2018). E-learning success determinants: Brazilian empirical study. Computers \& Education, 122(1), 273-290. https://doi.org/10.1016/j.compedu.2017.12.001.

Costa, C. J., Ferreira, E., Bento, F., \& Aparicio, M. (2016). Enterprise resource planning adoption and satisfaction determinants. Computers in Human Behavior, 63(1), 659-671. https://doi.org/10.1016/j.chb.2016.05.090.

Cohen, J. (1988). Statistical Power Analysis for the Behavioral Sciences (2nd ed.). Hillsdale, NJ: Lawrence Erlbaum Associates.

Curşeu, P. L., Rusu, A., Maricuțoiu, L. P., Virgă, D., \& Măgurean, S. (2020). Identified and engaged: A multi-level dynamic model of identification with the group and performance in collaborative learning. Learning and Individual Differences, 78, 101838. https://doi.org/10.1016/.lindif.2020.101838.

Dado, M., \& Bodemer, D. (2017). A review of methodological applications of social network analysis in computer-supported collaborative learning. Educational Research Review, 22, 159-180. https://doi.org/10.1016/j.edurev.2017.08.005.

Davis, F. D. (1989). Perceived usefulness, perceived ease of use, and user acceptance of information technology. MIS Quarterly, 13(3), 319-340. https://doi.org/10.2307/249008.

DeLone, W. H., \& McLean, E. R. (1992). Information systems success: The quest for the dependent variable. Information Systems Research, 3(1), 60-95. https://doi.org/10.1287/isre.3.1.60.

DeLone, W. H., \& McLean, E. R. (2003). The DeLone and McLean model of information systems success: A ten-year update. Journal of Management Information Systems, 19(4), 9-30. https://doi.org/10.1080/07421222.2003.11045748.

DeLone, W. H., \& McLean, E. R. (2004). Measuring e-commerce success: Applying the DeLone \& McLean information systems success model. International Journal of Electronic Commerce, 9(1), 31-47. https://doi.org/10.1080/10864415.2004.11044317.

Deng, L., \& Tavares, N. J. (2013). From Moodle to Facebook: Exploring students' motivation and experiences in online communities. Computers \& Education, 68(1), 167-176. https://doi.org/10.1016/j.compedu.2013.04.028.

Doumanis, I., Economou, D., Sim, G. R., \& Porter, S. (2019). The impact of multimodal collaborative virtual environments on learning: A gamified online debate. Computers \& Education, 130, 121-138. https://doi.org/10.1016/j.compedu.2018.09.017.

Elia, G., Solazzo, G., Lorenzo, G., \& Passiante, G. (2019). Assessing learners' satisfaction in collaborative online courses through a big data approach. Computers in Human Behavior, 92, 589-599. https://doi.org/10.1016/j.chb.2018.04.033.

El-Masri, M., \& Tarhini, A. (2017). Factors affecting the adoption of e-learning systems in Qatar and USA: Extending the unified theory of acceptance and use of technology 2 (UTAUT2). Educational Technology Research and Development, 65(3), 743763. https://doi.org/10.1007/s11423-016-9508-8.

Farooq, M. S. (2018). Modelling the significance of social support and entrepreneurial skills for determining entrepreneurial behaviour of individuals. World Journal of Entrepreneurship, Management and Sustainable Development, 14(3), 242-266. https://doi.org/10.1108/WJEMSD-12-2017-0096.

Farooq, M. S., \& Salam, M. (2020). Nexus between CSR and DSIW: A PLS-SEM approach. International Journal of Hospitality Management, 86, 102437. https://doi.org/10.1016/j.jhm.2019.102437.

Farooq, M. S., Salam, M., Fayolle, A., Jaafar, N., \& Ayupp, K. (2018). Impact of service quality on customer satisfaction in Malaysia airlines: A PLS-SEM approach. Journal of Air Transport Management, 67(1), 169-180. https://doi.org/10.1016/j.jairtraman.2017.12.008.

Farooq, M. S., Salam, M., Jaafar, N., Fayolle, A., Ayupp, K., Radovic-Markovic, M., \& Sajid, A. (2017). Acceptance and use of lecture capture system (LCS) in executive business studies: Extending UTAUT2. Interactive Technology and Smart Education, 14(4), 329-348. https://doi.org/10.1108/TSE-06-2016-0015.

Farrokhnia, M., Pijeira-Díaz, H. J., Noroozi, O., \& Hatami, J. (2019). Computer-supported collaborative concept mapping: The effects of different instructional designs on conceptual understanding and knowledge co-construction. Computers \& Education, 142, 103640. https://doi.org/10.1016/j.compedu.2019.103640.

Finney, S., \& Corbett, M. (2007). ERP implementation: A compilation and analysis of critical success factors. Business Process Management Journal, 13(3), 329-347. https://doi.org/10.1108/14637150710752272.

Fleaca, E., \& Stanciu, R. D. (2019). Digital-age learning and business engineering education - A pilot study on students' E-skills. Procedia Manufacturing, 32, 1051-1057. https://doi.org/10.1016/.jpromfg.2019.02.320.

Fornell, C., \& Larcker, D. F. (1981). Structural equation models with unobservable variables and measurement error: Algebra and statistics. Journal of Marketing Research, 18(3), 382-388. https://doi.org/10.2307/3150980.

Forster, Y., Hergeth, S., Naujoks, F., Krems, J. F., \& Keinath, A. (2020). What and how to tell beforehand: The effect of user education on understanding, interaction and satisfaction with driving automation. Transportation Research Part F: Traffic Psychology and Behaviour, 68, 316-335. https://doi.org/10.1016/j.trf.2019.11.017. 
Gao, L., \& Bai, X. (2014). An empirical study on continuance intention of Mobile social networking services: Integrating the IS success model, network externalities and flow theory. Asia Pacific Journal of Marketing and Logistics, 26(2), 168-189. https://doi.org/10.1108/APJML-07-2013-0086.

Gao, Q., Dai, Y., Fan, Z., \& Kang, R. (2010). Understanding factors affecting perceived sociability of social software. Computers in Human Behavior, 26(6), 1846-1861. https://doi.org/10.1016/j.chb.2010.07.022.

Garcia-Sanjuan, F., Jurdi, S., Jaen, J., \& Nacher, V. (2018). Evaluating a tactile and a tangible multi-tablet gamified quiz system for collaborative learning in primary education. Computers \& Education, 123, 65-84. https://doi.org/10.1016/j.compedu. 2018.04.011.

Geisser, S. (1974). A predictive approach to the random effects model. Biometrika, 61(1), 101-107. https://doi.org/10.1093/ biomet/61.1.101.

Gelderman, M. (1998). The relation between user satisfaction, usage of information systems and performance. Information \& Management, 34(1), 11-18. https://doi.org/10.1016/S0378-7206(98)00044-5.

Gerber, A., Dietzsch, M., \& Althaus, K. (2004). Information based, dynamic quality information system for non-hierarchic regional production networks. Robotics and Computer-Integrated Manufacturing, 20(6), 583-591. https://doi.org/10.1016/j. rcim.2004.06.003.

Gluck, M. (1996). Exploring the relationship between user satisfaction and relevance in information systems. Information Processing \& Management, 32(1), 89-104. https://doi.org/10.1016/0306-4573(95)00031-B.

Grabowski, M., \& Roberts, K. H. (2019). Reliability seeking virtual organizations: Challenges for high reliability organizations and resilience engineering. Safety Science, 117, 512-522. https://doi.org/10.1016/j.ssci.2016.02.016.

Gress, C. L. Z., Fior, M., Hadwin, A. F., \& Winne, P. H. (2010). Measurement and assessment in computer-supported collaborative learning. Computers in Human Behavior, 26(5), 806-814. https://doi.org/10.1016/j.chb.2007.05.012.

Gunawardena, C. N. (1995). Social presence theory and implications for interaction and collaborative learning in computer conferences. International Journal of Educational Telecommunications, 1(2), 147-166.

Hair, J., Hollingsworth, C. L., Randolph, A. B., \& Chong, A. Y. L. (2017). An updated and expanded assessment of PLS-SEM in information systems research. Industrial Management \& Data Systems, 117(3), 442-458. https://doi.org/10.1108/IMDS-042016-0130.

Hair, J. F., Hult, T. M. G., Ringle, C. M., \& Sarstedt, M. (Eds.) (2014). A primer on partial least squares structural equation modeling (PLS-SEM). LOS Angeles: Sage.

Hair, J. F., Ringle, C. M., \& Sarstedt, M. (2011). PLS-SEM: Indeed a Silver bullet. Journal of Marketing Theory and Practice, 19(2), 139-152. https://doi.org/10.2753/MTP1069-6679190202.

Hamidi, H., \& Jahanshaheefard, M. (2019). Essential factors for the application of education information system using mobile learning: A case study of students of the university of technology. Telematics and Informatics, 38, 207-224. https://doi. org/10.1016/j.tele.2018.10.002.

Handayani, P. W., Pinem, A. A., Azzahro, F., Hidayanto, A. N., \& Ayuningtyas, D. (2019). The information system/information technology (IS/IT) practices in the Indonesia health referral system. Informatics in Medicine Unlocked, 17, 100263. https:// doi.org/10.1016/j.imu.2019.100263.

Haque, M. M., Chin, H. C., \& Huang, H. (2009). Modeling fault among motorcyclists involved in crashes. Accident Analysis \& Prevention, 41(2), 327-335. https://doi.org/10.1016/j.aap.2008.12.010.

Hassanzadeh, A., Kanaani, F., \& Elahi, S. (2012). A model for measuring e-learning systems success in universities. Expert Systems with Applications, 39(12), 10959-10966. https://doi.org/10.1016/j.eswa.2012.03.028.

Hendra, S., \& Arifin, Y. (2018). Web-based usability measurement for student grading information system. Procedia Computer Science, 135, 238-247. https://doi.org/10.1016/j.procs.2018.08.171.

Henseler, J., Ray, P. A., \& Hubona, G. (2016). Using PLS path modeling in new technology research: Updated guidelines. Industrial Management \& Data Systems, 116(1), 2-20. https://doi.org/10.1108/IMDS-09-2015-0382.

Henseler, J., Ringle, C. M., \& Sarstedt, M. (2015). A new criterion for assessing discriminant validity in variance-based structural equation modeling. Journal of the Academy of Marketing Science, 43(1), 115-135. https://doi.org/10.1007/s11747-014-0403-8.

Henseler, J., Ringle, C. M., \& Sinkovics, R. R. (2009). Advances in International Marketing. https:/doi.org/10.1108/S1474-7979(2009)0000020014.

Hernández-Sellés, N., Muñoz-Carril, P.-C., \& González-Sanmamed, M. (2019). Computer-supported collaborative learning: An analysis of the relationship between interaction, emotional support and online collaborative tools. Computers \& Education, 138, 1-12. https://doi.org/10.1016/j.compedu.2019.04.012.

Holenko Dlab, M., Boticki, I., Hoic-Bozic, N., \& Looi, C. K. (2020). Exploring group interactions in synchronous mobile computersupported learning activities. Computers \& Education, 146, 103735. https://doi.org/10.1016/j.compedu.2019.103735.

Hoppe, H. U., Soller, A., \& Ogata, H. (Eds.) (2007). The role of technology in CSCL: Studies in technology enhanced collaborative learning, (1st ed., ). New York: Springer.

Isohätälä, J., Järvenoja, H., \& Järvelä, S. (2017). Socially shared regulation of learning and participation in social interaction in collaborative learning. International Journal of Educational Research, 81, 11-24. https://doi.org/10.1016/j.jijer.2016.10.006.

Jan, J.-C., Chen, C.-M., \& Huang, P.-H. (2016). Enhancement of digital reading performance by using a novel web-based collaborative reading annotation system with two quality annotation filtering mechanisms. International Journal of Human-Computer Studies, 86, 81-93. https://doi.org/10.1016/j.jihcs.2015.09.006.

Jeong, H., Hmelo-Silver, C. E., \& Jo, K. (2019). Ten years of computer-supported collaborative learning: A meta-analysis of CSCL in STEM education during 2005-2014. Educational Research Review, 28, 100284. https://doi.org/10.1016/j.edurev.2019.100284.

Jiang, D., \& Zhang, L. J. (2020). Collaborating with 'familiar' strangers in mobile-assisted environments: The effect of socializing activities on learning EFL writing. Computers \& Education, 150, 103841. https://doi.org/10.1016/j.compedu.2020.103841.

Junglas, l., Goel, L., Abraham, C., \& Ives, B. (2013). The social component of information systems- How sociability contributes to technology acceptance. Journal of the Association for Information Systems, 14(10), 585-616. https://doi.org/10.17705/1jais.00344.

Kim, M. K., Wang, Y., \& Ketenci, T. (2020). Who are online learning leaders? Piloting a leader identification method (LIM). Computers in Human Behavior, 105, 106205. https://doi.org/10.1016/j.chb.2019.106205.

Kim, S. S., \& Malhotra, N. K. (2005). A longitudinal model of continued IS use: An integrative view of four mechanisms underlying postadoption phenomena. Management Science, 51(5), 741-755. https://doi.org/10.1287/mnsc.1040.0326.

Kreijns, K, \& Kirschner, P. A. (2004). Designing sociable CSCL environments. In J.-W. Strijbos, P. Kirschner, \& R. L. Martens (Eds.), What we know about CSCL: And implementing it in higher education, (pp. 221-243). https:/doi.org/10.1007/1-4020-7921-4_9. 
Kreijns, K., Kirschner, P. A., \& Jochems, W. (2002). The sociability of computer-supported collaborative learning environments. Educational Technology \& Society, 5(1), 8-22.

Kreijns, K., Kirschner, P. A., Jochems, W., \& van Buuren, H. (2004). Determining sociability, social space, and social presence in (a) synchronous collaborative groups. Cyberpsychology \& Behavior, 7(2), 155-172. https://doi.org/10.1089/ 109493104323024429.

Kreijns, K., Kirschner, P. A., Jochems, W., \& van Buuren, H. (2007). Measuring perceived sociability of computer-supported collaborative learning environments. Computers \& Education, 49(2), 176-192. https://doi.org/10.1016/j.compedu.2005.05. 004 .

Kreijns, K., Kirschner, P. A., \& Vermeulen, M. (2013). Social aspects of CSCL environments: A research framework. Educational Psychologist, 48(4), 229-242. https://doi.org/10.1080/00461520.2012.750225.

Kreijns, K., Van Acker, F., Vermeulen, M., \& Van Buuren, H. (2014). Community of Inquiry: Social presence revisited. E-Learning and Digital Media, 11(1), 5-18. https://doi.org/10.2304/elea.2014.11.1.5.

Krishnakumar, J., \& Nogales, R. (2020). Education, skills and a good job: A multidimensional econometric analysis. World Development, 128, 104842. https://doi.org/10.1016/j.worlddev.2019.104842.

Kurilovas, E., \& Kubilinskiene, S. (2020). Lithuanian case study on evaluating suitability, acceptance and use of IT tools by students - An example of applying technology enhanced learning research methods in higher education. Computers in Human Behavior, 107, 106274. https://doi.org/10.1016/j.chb.2020.106274.

Kurkalova, L. A., \& Carter, L. (2017). Sustainable production: Using simulation modeling to identify the benefits of green information systems. Decision Support Systems, 96, 83-91. https://doi.org/10.1016/j.dss.2017.02.006.

Lee, S.-M. (2014). The relationships between higher order thinking skills, cognitive density, and social presence in online learning. The Internet and Higher Education, 21, 41-52. https://doi.org/10.1016/j.iheduc.2013.12.002.

Li, Y., \& Shang, H. (2019). Service quality, perceived value, and citizens' continuous-use intention regarding e-government: Empirical evidence from China. Information \& Management, 103197. https://doi.org/10.1016/j.im.2019.103197.

Li, Z., Huang, D., Liu, X., Xie, N., \& Zhang, G. (2020). Information structures in a covering information system. Information Sciences, 507, 449-471. https://doi.org/10.1016/.jins.2018.09.048.

Liao, Y.-W., Huang, Y.-M., Chen, H.-C., \& Huang, S.-H. (2015). Exploring the antecedents of collaborative learning performance over social networking sites in a ubiquitous learning context. Computers in Human Behavior, 43(Supplement C), 313-323. https://doi.org/10.1016/j.chb.2014.10.028.

Liaw, S.-S., Chen, G.-D., \& Huang, H.-M. (2008). Users' attitudes toward web-based collaborative learning systems for knowledge management. Computers \& Education, 50(3), 950-961. https://doi.org/10.1016/j.compedu.2006.09.007.

Lin, G.-Y. (2020). Scripts and mastery goal orientation in face-to-face versus computer-mediated collaborative learning: Influence on performance, affective and motivational outcomes, and social ability. Computers \& Education, 143, 103691. https://doi.org/10.1016/j.compedu.2019.103691.

Lin, M., Preston, A., Kharrufa, A., \& Kong, Z. (2016). Making L2 learners' reasoning skills visible: The potential of computer supported collaborative learning environments. Thinking Skills and Creativity, 22, 303-322. https://doi.org/10.1016/j.tsc 2016.06.004.

Love, P. E. D., Matthews, J., \& Zhou, J. (2020). Is it just too good to be true? Unearthing the benefits of disruptive technology. International Journal of Information Management, 102096. https://doi.org/10.1016/j.ijinfomgt.2020.102096.

Lowton-Smith, S., Morgan, R., Stanley, M., Hames, T., Smith, P., Lawson, C., \& Leddington Wright, S. (2019). Peer-to-peer teaching: Experience of 3rd year undergraduate sports therapy students and impact upon applied academic performance. Journal of Hospitality, Leisure, Sport \& Tourism Education, 25, 100196. https://doi.org/10.1016/j.jhlste.2019.04.002.

Makhni, E. C. (2020). Editorial commentary: Making the leap to the patient-reported outcomes measurement information system: A paradigm shift that will ultimately benefit our patients. Arthroscopy: The Journal of Arthroscopic \& Related Surgery, 36(2), 521-523. https://doi.org/10.1016/j.arthro.2019.12.001.

Mamun, M. A. A., Lawrie, G., \& Wright, T. (2020). Instructional design of scaffolded online learning modules for self-directed and inquiry-based learning environments. Computers \& Education, 144, 103695. https://doi.org/10.1016/j.compedu.2019.103695.

Marnewick, C. (2016). Benefits of information system projects: The tale of two countries. International Journal of Project Management, 34(4), 748-760. https://doi.org/10.1016/j.jproman.2015.03.016.

Martins, J., Branco, F., Gonçalves, R., Au-Yong-Oliveira, M., Oliveira, T., Naranjo-Zolotov, M., \& Cruz-Jesus, F. (2018). Assessing the success behind the use of education management information systems in higher education. Telematics and Informatics, 38(1), 182-193. https://doi.org/10.1016/j.tele.2018.10.001.

Mata-Rivera, F., Torres-Ruiz, M., Guzmán, G., Moreno-lbarra, M., \& Quintero, R. (2015). A collaborative learning approach for geographic information retrieval based on social networks. Computers in Human Behavior, 51, 829-842. https://doi.org/10.1016/j.chb.2014.11.069.

Mellikeche, S., de Fatima Marin, H., Benítez, S. E., de Lira, A. C. O., de Quirós, F. G. B., \& Degoulet, P. (2020). External validation of the unified model of information systems continuance (UMISC): An international comparison. International Journal of Medical Informatics, 134, 103927. https://doi.org/10.1016/j.jmedinf.2019.07.006.

Michel-Verkerke, M. B. (2012). Information quality of a nursing information system depends on the nurses: A combined quantitative and qualitative evaluation. International Journal of Medical Informatics, 81(10), 662-673. https://doi.org/10. 1016/j.jijmedinf.2012.07.006.

Mills, A., \& Durepos, G. (2010). Social-interaction theory. In E. Wiebe (Ed.), Encyclopedia of case study research. https://doi.org/ 10.4135/9781412957397.n322.

Modaresnezhad, M., Iyer, L., Palvia, P., \& Taras, V. (2020). Information technology (IT) enabled crowdsourcing: A conceptual framework. Information Processing \& Management, 57(2), 102135. https://doi.org/10.1016/j.ipm.2019.102135.

Mohammadi, H. (2015). Investigating users' perspectives on e-learning: An integration of TAM and IS success model. Computers in Human Behavior, 45(1), 359-374. https://doi.org/10.1016/j.chb.2014.07.044.

Molinillo, S., Aguilar-Illescas, R., Anaya-Sánchez, R., \& Vallespín-Arán, M. (2018a). Exploring the impacts of interactions, socia presence and emotional engagement on active collaborative learning in a social web-based environment. Computers \& Education, 123(1), 41-52. https://doi.org/10.1016/j.compedu.2018.04.012 .

Molinillo, S., Anaya-Sánchez, R., Aguilar-Illescas, R., \& Vallespín-Arán, M. (2018b). Social media-based collaborative learning: Exploring antecedents of attitude. The Internet and Higher Education, 38, 18-27. https://doi.org/10.1016/j.iheduc.2018.04.003. 
Muczyński, A., Dawidowicz, A., \& Źróbek, R. (2019). The information system for social housing management as a part of the land administration system - A case study of Poland. Land Use Policy, 86, 165-176. https://doi.org/10.1016/.landusepol.2019.04.039.

Mukred, M., \& Yusof, Z. M. (2018). The DeLone-McLean information system success model for electronic records management system adoption in higher professional education institutions of Yemen. In F. Saeed, N. Gazem, S. Patnaik, A. S. S. Balaid, \& F. Mohammed (Eds.), Recent trends in information and communication technology, (vol. 5, pp. 812-823). https://doi.org/10.1007/978-3-319-59427-9_84.

Njenga, K., Garg, L., Bhardwaj, A. K., Prakash, V., \& Bawa, S. (2019). The cloud computing adoption in higher learning institutions in Kenya: Hindering factors and recommendations for the way forward. Telematics and Informatics, 38, 225246. https://doi.org/10.1016/j.tele.2018.10.007.

Ojo, A. I. (2017). Validation of the DeLone and McLean information systems success model. Healthcare Informatics Research, 23(1), 60. https://doi.org/10.4258/hir.2017.23.1.60

Oksanen, K., \& Hämäläinen, R. (2013). Perceived sociability and social presence in a collaborative serious game. International Journal of Game-Based Learning, 3(1), 34-50. https://doi.org/10.4018/ijgbl.2013010103.

Oviedo-Trespalacios, O., Briant, O., Kaye, S.-A., \& King, M. (2020). Assessing driver acceptance of technology that reduces mobile phone use while driving: The case of mobile phone applications. Accident Analysis \& Prevention, 135, 105348. https://doi.org/10.1016/j.aap.2019.105348.

Peña-Miguel, N., \& De La Peña, J. I. (2018). New accounting information system: An application for a basic social benefit in Spain. Revista de Contabilidad, 21(1), 28-37. https://doi.org/10.1016/j.rcsar.2017.07.002.

Pinho, C., Franco, M., \& Mendes, L. (2019). Exploring the conditions of success in e-libraries in the higher education context through the lens of the social learning theory. Information \& Management, 103208. https://doi.org/10.1016/j.im.2019.103208.

Prys, M., Krysińska, J., Janaszkiewicz, P., Winiecki, P., \& Różewski, P. (2018). System analysis of human capital for information system development. Procedia Computer Science, 126, 1197-1205. https://doi.org/10.1016/j.procs.2018.08.060.

Radianti, J., Majchrzak, T. A., Fromm, J., \& Wohlgenannt, I. (2020). A systematic review of immersive virtual reality applications for higher education: Design elements, lessons learned, and research agenda. Computers \& Education, 147, 103778. https://doi.org/10.1016/j.compedu.2019.103778.

Rajab, M., \& Eydgahi, A. (2019). Evaluating the explanatory power of theoretical frameworks on intention to comply with information security policies in higher education. Computers \& Security, 80, 211-223. https://doi.org/10.1016/j.cose.2018.09.016.

Rangraz Jeddi, F., Nabovati, E., Bigham, R., \& Khajouei, R. (2020). Usability evaluation of a comprehensive national health information system: Relationship of quality components to users' characteristics. International Journal of Medical Informatics, 133, 104026. https://doi.org/10.1016/j.jmedinf.2019.104026.

Rehak, D. (2020). Assessing and strengthening organisational resilience in a critical infrastructure system: Case study of the Slovak Republic. Safety Science, 123, 104573. https://doi.org/10.1016/..ssci.2019.104573.

Reis, R. C. D., Isotani, S., Rodriguez, C. L., Lyra, K. T., Jaques, P. A., \& Bittencourt, I. I. (2018). Affective states in computersupported collaborative learning: Studying the past to drive the future. Computers \& Education, 120, 29-50. https://doi. org/10.1016/j.compedu.2018.01.015.

Riesener, M., Dölle, C., Schuh, G., \& Tönnes, C. (2019). Framework for defining information quality based on data attributes within the digital shadow using LDA. Procedia CIRP, 83, 304-310. https://doi.org/10.1016/j.procir.2019.03.131.

Rizal, H., Yussof, S., Amin, H., \& Chen-Jung, K. (2018). EWOM towards homestays lodging: Extending the information system success model. Journal of Hospitality and Tourism Technology, 9(1), 94-108. https://doi.org/10.1108/JHTT-12-2016-0084.

Rosen, Y., Wolf, I., \& Stoeffler, K. (2019). Fostering collaborative problem solving skills in science: The Animalia project. Computers in Human Behavior, 105922. https://doi.org/10.1016/j.chb.2019.02.018.

Salam, M. (2020). A technology integration framework and co-operative reflection model for service learning (PhD Thesis, Universiti Malaysia Sarawak (UNIMAS)). Retrieved from https://ir.unimas.my/id/eprint/28754/.

Salam, M., Awang Iskandar, D. N., Ibrahim, D. H. A., \& Farooq, M. S. (2019a). Service learning in higher education: A systematic literature review. Asia Pacific Education Review, 20(4), 573-593. https://doi.org/10.1007/s12564-019-09580-6.

Salam, M., Awang Iskandar, D. N., Ibrahim, D. H. A., \& Farooq, M. S. (2019b). Technology integration in service-learning pedagogy: A holistic framework. Telematics and Informatics, 38(1), 257-273. https://doi.org/10.1016/j.tele.2019.02.002.

Salmela, H. (1997). From information systems quality to sustainable business quality. Information and Software Technology, 39(12), 819-825. https://doi.org/10.1016/50950-5849(97)00040-2.

Santa, R., MacDonald, J. B., \& Ferrer, M. (2019). The role of trust in e-government effectiveness, operational effectiveness and user satisfaction: Lessons from Saudi Arabia in e-G2B. Government Information Quarterly, 36(1), 39-50. https://doi.org/10.1016/j.giq.2018.10. 007.

Segars, A. H. (1997). Assessing the unidimensionality of measurement: A paradigm and illustration within the context of information systems research. Omega, 25(1), 107-121. https://doi.org/10.1016/S0305-0483(96)00051-5.

Shanmugapriya, S., \& Subramanian, K. (2015). Structural equation model to investigate the factors influencing quality performance in Indian construction projects. Sadhana, 40(6), 1975-1987. https://doi.org/10.1007/s12046-015-0421-3.

Shen, B. (2012). Research and practice on web 2.0-based collaborative learning. IERI Procedia, 2, 655-659. https://doi.org/10.1016/.jeri.2012. 06.149 .

Shen, C., \& Ho, J. (2020). Technology-enhanced learning in higher education: A bibliometric analysis with latent semantic approach. Computers in Human Behavior, 104, 106177. https://doi.org/10.1016/j.chb.2019.106177.

Shim, M., \& Jo, H. S. (2020). What quality factors matter in enhancing the perceived benefits of online health information sites? Application of the updated DeLone and McLean information systems success model. International Journal of Medical Informatics, 137, 104093. https://doi.org/10.1016/j.jmedinf.2020.104093.

Shuell, T. J. (2001). Learning theories and educational paradigms. In N. J. Smelser, \& P. B. Baltes (Eds.), International encyclopedia of the Social \& Behavioral Sciences, (pp. 8613-8620). https://doi.org/10.1016/B0-08-043076-7/02385-8.

Smith, E. E. (2016). "A real double-edged sword:" undergraduate perceptions of social media in their learning. Computers \& Education, 103, 44-58. https://doi.org/10.1016/j.compedu.2016.09.009.

Stone, M. (1974). Cross-Validatory choice and assessment of statistical predictions. Journal of the Royal Statistical Society: Series B: Methodological, 36(2), 111-133. https://doi.org/10.1111/j.2517-6161.1974.tb00994.x.

Suebnukarn, S., \& Haddawy, P. (2006). A Bayesian approach to generating tutorial hints in a collaborative medical problembased learning system. Artificial Intelligence in Medicine, 38(1), 5-24. https://doi.org/10.1016/j.artmed.2005.04.003. 
Tam, C., \& Oliveira, T. (2016). Understanding the impact of m-banking on individual performance: DeLone \& McLean and TTF perspective. Computers in Human Behavior, 61(1), 233-244. https://doi.org/10.1016/j.chb.2016.03.016.

Tam, C., \& Oliveira, T. (2017). Understanding mobile banking individual performance: The DeLone \& McLean model and the moderating effects of individual culture. Internet Research, 27(3), 538-562. https://doi.org/10.1108/IntR-05-2016-0117.

Tan, H. C. (2019). Using a structured collaborative learning approach in a case-based management accounting course. Journal of Accounting Education, 49, 100638. https://doi.org/10.1016/j.jaccedu.2019.100638.

Tao, D., Wang, T., Wang, T., Zhang, T., Zhang, X., \& Qu, X. (2020). A systematic review and meta-analysis of user acceptance of consumer-oriented health information technologies. Computers in Human Behavior, 104, 106147. https://doi.org/10.1016/j. chb.2019.09.023.

Tenenhaus, M., Esposito Vinzi, V., Chatelin, Y.-M., \& Lauro, C. (2005). PLS path modeling. Computational Statistics \& Data Analysis, 48(1), 159-205. https://doi.org/10.1016/j.csda.2004.03.005.

Tennyson, R. D., \& Volk, A. (2015). Learning theories and educational paradigms. In J. D. Wright (Ed.), International encyclopedia of the Social \& Behavioral Sciences (second edition), (pp. 699-711). https://doi.org/10.1016/B978-0-08-097086-8.92036-1.

Tarhini, A., Masa'deh, R., Al-Busaidi, K. A., Mohammed, A. B., \& Maqableh, M. (2017). Factors influencing students' adoption of e-learning: A structural equation modeling approach. Journal of International Education in Business, 10(2), 164-182. https://doi.org/10.1108/JIEB-09-2016-0032.

Timmerman, Y., \& Bronselaer, A. (2019). Measuring data quality in information systems research. Decision Support Systems, 126, 113138. https://doi.org/10.1016/j.dss.2019.113138.

Tsertsidis, A., Kolkowska, E., \& Hedström, K. (2019). Factors influencing seniors' acceptance of technology for ageing in place in the post-implementation stage: A literature review. International Journal of Medical Informatics, 129, 324-333. https:// doi.org/10.1016/.i.jmedinf.2019.06.027.

Urbach, N., Smolnik, S., \& Riempp, G. (2010). An empirical investigation of employee portal success. The Journal of Strategic Information Systems, 19(3), 184-206. https://doi.org/10.1016/j.jsis.2010.06.002.

Veeramootoo, N., Nunkoo, R., \& Dwivedi, Y. K. (2018). What determines success of an e-government service? Validation of an integrative model of e-filing continuance usage. Government Information Quarterly, 35(2), 161-174. https://doi.org/10. 1016/j.giq.2018.03.004.

Venkatesh, V., Morris, M. G., Davis, G. B., \& Davis, F. D. (2003). User acceptance of information technology: Toward a unified view. MIS Quarterly, 27(3), 425-478.

Venkatesh, V., Thong, J. Y., \& Xu, X. (2012). Consumer acceptance and use of information technology: Extending the unified theory of acceptance and use of technology. MIS Quarterly, 36(1), 157-178.

Vitale, K. R., \& Udell, M. A. R. (2019). The quality of being sociable: The influence of human attentional state, population, and human familiarity on domestic cat sociability. Behavioural Processes, 158, 11-17. https://doi.org/10.1016/j.beproc.2018.10.026.

von Hellens, L. A. (1997). Information systems quality versus software quality a discussion from a managerial, an organisational and an engineering viewpoint. Information and Software Technology, 39(12), 801-808. https://doi.org/10.1016/50950-5849(97)00038-4.

Wang, C., Fang, T., \& Gu, Y. (2020). Learning performance and behavioral patterns of online collaborative learning: Impact of cognitive load and affordances of different multimedia. Computers \& Education, 143, 103683. https://doi.org/10.1016/j. compedu.2019.103683.

Wang, C., \& Teo, T. S. H. (2020). Online service quality and perceived value in mobile government success: An empirical study of mobile police in China. International Journal of Information Management, 102076. https://doi.org/10.1016/.jijifomgt.2020.102076.

Wang, G., \& Zhao, W. (2020). Chapter 5-Integrated technology of avionics system functional organization. In G. Wang, \& W. Zhao (Eds.), The principles of integrated Technology in Avionics Systems, (pp. 235-294). https://doi.org/10.1016/B978-0-12-816651-2.00005-8.

Wang, H. C., \& Chiu, Y. F. (2011). Assessing e-learning 2.0 system success. Computers \& Education, 57(2), 1790-1800. https://doi. org/10.1016/j.compedu.2011.03.009.

Wang, W., \& Wang, C.-C. (2009). An empirical study of instructor adoption of web-based learning systems. Computers \& Education, 53(3), 761-774. https://doi.org/10.1016/j.compedu.2009.02.021.

Wang, Y.-S., \& Liao, Y.-W. (2008). Assessing eGovernment systems success: A validation of the DeLone and McLean model of information systems success. Government Information Quarterly, 25(4), 717-733. https://doi.org/10.1016/j.giq.2007.06.002.

Ward, R. (1998). Active, collaborative and case-based learning with computer-based case scenarios. Computers \& Education, 30(1), 103-110. https://doi.org/10.1016/S0360-1315(97)00085-7.

Wasko, M. M., \& Faraj, S. (2005). Why should I share? Examining social capital and knowledge contribution in electronic networks of practice. MIS Quarterly, 29(1), 35-57. https://doi.org/10.2307/25148667.

Weimer, A. A., Parault Dowds, S. J., Fabricius, W. V., Schwanenflugel, P. J., \& Suh, G. W. (2017). Development of constructivist theory of mind from middle childhood to early adulthood and its relation to social cognition and behavior. Journal of Experimental Child Psychology, 154, 28-45. https://doi.org/10.1016/j.jecp.2016.10.002.

Wetzels, M., Odekerken-Schröder, G., \& van Oppen, C. (2009). Using PLS path modeling for assessing hierarchical construct models: Guidelines and empirical illustration. MIS Quarterly, 33(1), 177-195. https://doi.org/10.2307/20650284.

White, D. J., Watts, E., Pitchforth, K., Agyapong, S., \& Miller, N. (2017). 'Sociability' affects the intensity of mate-choice copying in female guppies, Poecilia reticulata. Behavioural Processes, 141, 251-257. https://doi.org/10.1016/j.beproc.2017.02.017.

Williamson, G. R., Plowright, H., Kane, A., Bunce, J., Clarke, D., \& Jamison, C. (2020). Collaborative learning in practice: A systematic review and narrative synthesis of the research evidence in nurse education. Nurse Education in Practice, 43, 102706. https://doi.org/10.1016/j.nepr.2020.102706.

$\mathrm{Xu}, \mathrm{F}$., \& Du, J. T. (2019). Examining differences and similarities between graduate and undergraduate students' user satisfaction with digital libraries. The Journal of Academic Librarianship, 45(6), 102072. https://doi.org/10.1016/j.acalib.2019.102072.

Yamada, M., Goda, Y., Matsukawa, H., Hata, K., \& Yasunami, S. (2016). A computer-supported collaborative learning design for quality interaction. IEEE Multimedia, 23(1), 48-59. https://doi.org/10.1109/MMUL.2015.95.

Yang, M., Shao, Z., Liu, Q., \& Liu, C. (2017). Understanding the quality factors that influence the continuance intention of students toward participation in MOOCs. Educational Technology Research and Development, 65(5), 1195-1214. https://doi. org/10.1007/s11423-017-9513-6.

Yang, W., \& Lam, P. T. I. (2019). Evaluation of drivers' benefits accruing from an intelligent parking information system. Journal of Cleaner Production, 231, 783-793. https://doi.org/10.1016/j.jclepro.2019.05.247. 
Yoder, M. L., Williford, A. P., \& Vitiello, V. E. (2019). Observed quality of classroom peer engagement in a sample of preschoolers displaying disruptive behaviors. Early Childhood Research Quarterly, 47, 206-217. https://doi.org/10.1016/j. ecresq.2018.12.011.

Yuan, Y., Chu, Z., Lai, F., \& Wu, H. (2020). The impact of transaction attributes on logistics outsourcing success: A moderated mediation model. International Journal of Production Economics, 219, 54-65. https://doi.org/10.1016/j.jpe.2019.04.038.

Zhang, B., Chen, S., D'Souza, W. D., \& Yi, B. (2020). A systematic quality assurance framework for the upgrade of radiation oncology information systems. Physica Medica, 69, 28-35. https://doi.org/10.1016/j.ejmp.2019.11.024.

Zhang, L., \& Thompson, R. G. (2019). Understanding the benefits and limitations of occupancy information systems for couriers. Transportation Research Part C: Emerging Technologies, 105, 520-535. https://doi.org/10.1016/j.trc.2019.06.013.

Zheng, L., Li, X., Zhang, X., \& Sun, W. (2019). The effects of group metacognitive scaffolding on group metacognitive behaviors, group performance, and cognitive load in computer-supported collaborative learning. The Internet and Higher Education, 42, 13-24. https://doi.org/10.1016/j.iheduc.2019.03.002.

Zhou, N., Kisselburgh, L., Chandrasegaran, S., Badam, S. K., Elmqvist, N., \& Ramani, K. (2020). Using social interaction trace data and context to predict collaboration quality and creative fluency in collaborative design learning environments. International Journal of Human-Computer Studies, 136, 102378. https://doi.org/10.1016/j.ijhcs.2019.102378.

Zolotov, M. N., Oliveira, T., \& Casteleyn, S. (2018). Citizens' intention to use and recommend e-participation: Drawing upon UTAUT and citizen empowerment. Information Technology \& People, 32(2), 364-386. https://doi.org/10.1108/ITP-08-2017-0257.

\section{Publisher's Note}

Springer Nature remains neutral with regard to jurisdictional claims in published maps and institutional affiliations.

Submit your manuscript to a SpringerOpen ${ }^{\circ}$ journal and benefit from:

- Convenient online submission

- Rigorous peer review

- Open access: articles freely available online

High visibility within the field

- Retaining the copyright to your article

Submit your next manuscript at $\boldsymbol{\nabla}$ springeropen.com 